\title{
Cefazolin Concentration in Surgically Created Wounds Treated with Negative Pressure Wound Therapy Compared to Surgically Created Wounds Treated with Nonadherent Wound Dressings
}

\author{
Julia V. Coutin
}

Thesis submitted to the faculty of the Virginia Polytechnic Institute and State University in partial fulfillment of the requirements for the degree of

Master of Science

In

Biomedical and Veterinary Sciences

Otto I. Lanz, Chair

Marion F. Ehrich

Geraldine C. Magnin-Bissel

May 27, 2014

Blacksburg, VA

Keywords: Vacuum assisted closure, VAC, cefazolin, wound healing, negative pressure wound therapy

(C) 2014 Julia V. Coutin 
Cefazolin Concentration in Surgically Created Wounds Treated with Negative Pressure Wound Therapy Compared to Surgically Created Wounds Treated with Nonadherent Wound Dressings

\author{
Julia V. Coutin
}

\begin{abstract}
Our objective was to compare cefazolin concentrations in biopsied tissue samples collected from surgically created wounds treated with negative pressure wound therapy to those collected from surgically created wounds treated with nonadherent dressings. The study design was a prospective, controlled, experimental study. The animal population included 12 female spayed beagles. We hypothesized there would be a difference between the cefazolin concentrations of wounds treated with negative pressure wound therapy when compared to the cefazolin concentrations of wounds treated with nonadherent dressings.

Surgical methods were as follows: Full thickness cutaneous wounds were created on each antebrachium $(\mathrm{n}=24)$. Following surgery, cefazolin $(22 \mathrm{mg} / \mathrm{kg})$ was administered intravenously to each of the dogs and continued every 8 hours during the study. The right wound was randomly assigned to group I or group II while the wound on the contralateral antebrachium was assigned to the other group. Group I wounds were treated with negative pressure wound therapy (NPWT) and group II wounds were treated with nonadherent dressings for 3 days. Dressings were changed and tissue biopsies obtained from wound beds at 24-hour intervals for both groups. Cefazolin wound tissue and plasma concentrations were measured by liquid chromatography mass spectrometry (LCMS/MS). Blood samples for measuring plasma cefazolin concentrations were collected
\end{abstract}


prior to biopsy sampling. At the time of surgery and at each bandage change, wound beds were swabbed and submitted for aerobic and anaerobic culture.

Our results revealed that after initiating cefazolin treatment, wound tissue antibiotic concentrations between treatment groups were not significantly different at any sampling time. Similarly, after initiating cefazolin treatment, plasma cefazolin concentrations were not significantly different at any sampling time for individual dogs.

We concluded that using a canine experimental model, NPWT treatment of surgically created wounds does not statistically impact cefazolin tissue concentrations when compared to conventional nonadherent bandage therapy 


\section{ACKNOWLEDGEMENTS}

The author would like to acknowledge Dr. Otto Lanz for the inspiration and question which initiated this master's research. Additionally, the author would like to acknowledge the mentorship and instruction he provided over the course of the three year surgery residency/masters program.

The author would like to acknowledge Dr. Geraldine Magnin-Bissel and Dr. Marion Ehrich for their chemical expertise and assistance in running, obtaining, and quantifying the plasma and tissue cefazolin concentrations by liquid chromatography mass spectrometry.

I would also like to thank Dr. Stephen Werre for his expertise and contribution to the data in this thesis through statistical analysis.

Finally, I would like to thank the group of people who helped with the technical aspect of animal handling and sample acquisition for the research project. Without the assistance of Dana Callicote, Nicole Lindstrom, Karen Hall, and the emergency interns, the research would not have been able to be performed. 


\section{DECLARATION OF WORK}

The author declares that all liquid chromatography analysis was performed by Dr.

Geraldine Magnin-Bissel. Additionally, the author declares that the statistical analysis was performed by Dr. Steven Werre. 


\section{TABLE OF CONTENTS}

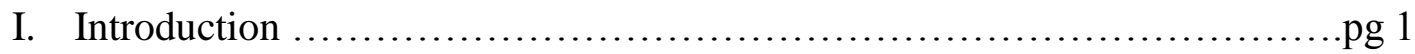

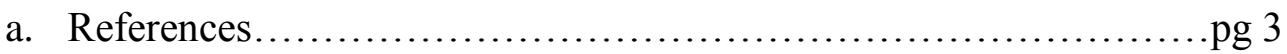

II. Negative Pressure Wound Therapy: Evolution, Pathophysiology, Indications,

Contraindications and Complications, and Application in Veterinary Medicine

a. Development of Negative Pressure in Wound Therapy................pg 6

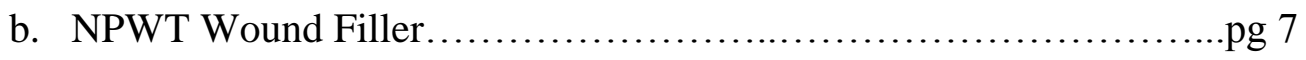

c. Negative Pressure Setting ........................................... 12

d. Physiology of Negative Pressure in Wound Healing..................pg 19

e. Indication, Contraindications, and Complications....................pg 29

f. NPWT in Veterinary Medicine.....................................pg 35

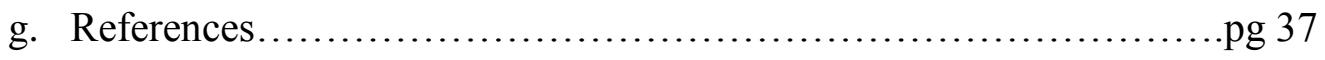

III. Liquid Chromatography Mass Spectrometry

a. Liquid Chromatography........................................ 52

b. Mass Spectrometry ................................................ 53

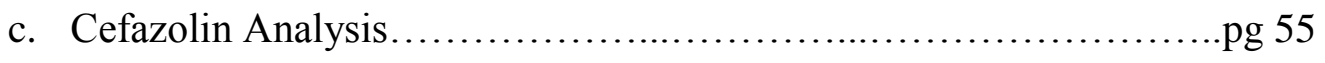

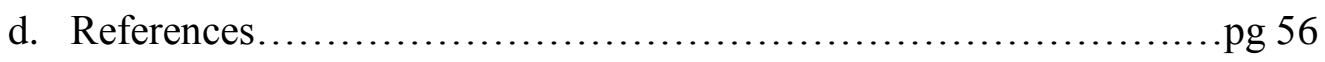

IV. Cefazolin

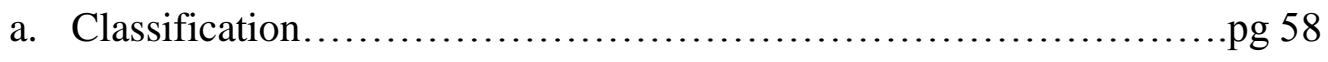

b. Mechanism of Action............................................... 59

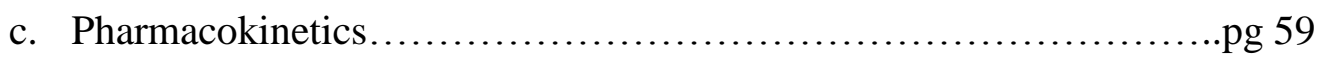

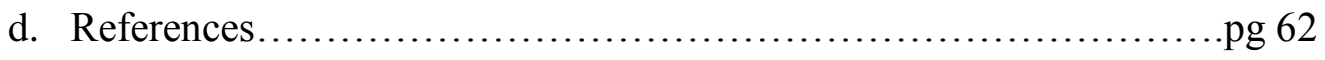


V. Cefazolin Concentration in Surgically Created Wounds Treated with Negative Pressure Wound Therapy Compared to Surgically Created Wounds Treated with Nonadherent Wound Dressings..................pg 64

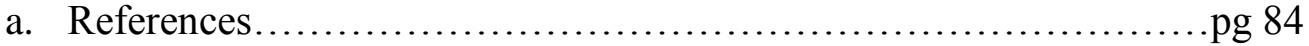

VI. Conclusions......................................................... 96 


\section{LIST OF TABLES}

Table 1 Wound Randomization..............................pg 91 


\section{LIST OF FIGURES}

Figure 1 Antebrachial Wound Outline........................pg 92

Figure 2 VAC Simplicity Unit...............................pg 93

Figure 3 Representative Study Dog..........................pg 94

Figure 4 Tissue Cefazolin Concentration.......................pg 95 


\section{ABBREVIATIONS}

NPWT

VAC

TNP

SAP

VST

SSS

PVA

PU

PDGF

IL

ATP

ADF

TGF

FGF

VEGF

ERK

JNK

vWF

MMP

TIMP

TNF

NGAL

LC-MS

HPLC

APCI

ESI

PBP

NMTT

PT

PTT

IV

IACUC

IM

SPE

LOD

LOQ

NA
Negative pressure wound therapy

Vacuum assisted closure

Topical negative pressure

Sub-atmospheric pressure

Vacuum sealing technique

Sealed surface wound suction

Polyvinyl alcohol

Polyurethane ether

Platelet derived growth factor

Interleukin

Adenosine triphosphate

Adenosine diphosphate

Transforming growth factor

Fibroblast growth factor

Vascular endothelial growth factor

Extracellular regulated kinase

Jun N-terminal protein kinase

Von Willebrands factor

Matrix metalloproteinase

Tissue inhibitor of metalloproteinase

Tumor necrosis factor

Neutrophil gelatinase-associated lipocalin

Liquid Chromatography-Mass Spectrometry

High performance liquid chromatography

Atmospheric-pressure chemical ionization

Electrospray ionization

Penicillin binding protein

$\mathrm{N}$-methylthiotetrazol

Prothrombin time

Partial thromboplastin time

Intravenous

Institutional Animal Care and Use Committee

Intramuscularly

Solid phase extraction

Limit of detection

Limit of quantitation

Nonadherent 


\section{Introduction}

Open wound management is commonly performed in veterinary medicine with a majority of treatments and dressings utilized dictated by veterinarian comfort and experience. Wound healing is complex and still a topic under investigation in human and veterinary literature. Because of the complexities and multifactorial nature of wound healing, there is a plethora of therapies which are aimed at optimizing the healing process. Recommended therapies used for treatment of open wounds include lavage solutions, topical antimicrobial agents, occlusive and semi-occlusive dressings, nonadherent dressings, oxygen therapy and systemic antimicrobials. ${ }^{1-3}$

Over ten years ago, Fleischmann and Morykwas introduced the concept of applying negative pressure to wounds in order to promote rapid wound healing. ${ }^{4,5}$ Negative pressure wound therapy (NPWT) was initially developed for the treatment of problematic wounds and for wound treatment either in preparation for surgery or as an alternative treatment to surgery in debilitated patients. ${ }^{6,7}$ Recent advancements and studies were conducted in order to add insight to the understanding of the mechanism of action of NPWT. NPWT is thought to promote wound healing by the early generation of granulation tissue, increasing local perfusion, reducing wound edema, altering chronic wound fluid composition, and cellular microdeformation. ${ }^{5,7-13}$ Although there are numerous studies investigating the mechanisms of action of NPWT, rapid wound healing seen with this modality is not completely understood. Despite recent advances, there is still minimal literature using NPWT in the veterinary clinical setting. ${ }^{14-21}$

Whether NPWT changes bacterial burden or even decreases it in open wounds is an area of debate. Our clinical observations have led us to hypothesize that regardless of 
superficial bacterial burden of wounds treated with NPWT, these wounds heal with more rapid granulation tissue formation then wounds treated with other traditional wound dressings. This study was undertaken in order to explore another mechanism by which NPWT could improve wound healing as compared to traditional nonadherent wound dressings; increase in local antibiotic concentration in the acute phase due to mechanisms previously investigated.

In the following investigation we have utilized an objective measure of local wound antibiotic concentration, compared antibiotic concentrations of wounds treated with NPWT to concentrations in wounds treated with nonadherent dressings, and compared systemic plasma concentrations between dogs. As a secondary investigation, superficial aerobic and anaerobic cultures were taken of each wound daily and results were compared. Our findings indicate that after initiating cefazolin treatment, wound tissue antibiotic concentrations between wounds treated with NPWT were not statistically different then antibiotic concentrations of wounds treated with traditional nonadherent dressings. Additionally we found that there was not statistically significant difference in bacterial burden in wounds treated with either NPWT or nonadherent dressings. These findings have led us to conclude that NPWT treatment of surgically created wounds does not statistically impact cefazolin tissue concentrations when compared to conventional nonadherent bandage therapy. Cefazolin tissue concentrations were similar between groups and therefore systemic cefazolin delivery to wounds treated with NPWT can be expected to be similar to the delivery in wounds treated with traditional nonadherent dressings. 


\section{Part Ia. References}

1. Krahwinkel DJ, Boothe HW, Jr.: Topical and systemic medications for wounds. Vet Clin North Am Small Anim Pract 36:739-757, 2006.

2. Fahie MA, Shettko D: Evidence-based wound management: a systematic review of therapeutic agents to enhance granulation and epithelialization. Vet Clin North Am Small Anim Pract 37:559-577, 2007.

3. Brumbaugh GW: Use of antimicrobials in wound management. Vet Clin North Am Equine Pract 21:63-75, 2005.

4. Fleischmann W, Becker U, Bischoff M, et al: Vacuum sealing: indication, technique, and results. European Journal of Orthopaedic Surgery \& Traumatology 5:37-40, 1995.

5. Morykwas MJ, Argenta LC, Shelton-Brown EI, et al: Vacuum-assisted closure: a new method for wound control and treatment: animal studies and basic foundation. Ann Plast Surg 38:553-562, 1997.

6. Argenta LC, Morykwas MJ: Vacuum-assisted closure: a new method for wound control and treatment: clinical experience. Ann Plast Surg 38:563-576; discussion $577,1997$.

7. Plikaitis CM, Molnar JA: Subatmospheric pressure wound therapy and the vacuumassisted closure device: basic science and current clinical successes. Expert Rev Med Devices 3:175-184, 2006.

8. Hunter JE, Teot L, Horch R, et al: Evidence-based medicine: vacuum-assisted closure in wound care management. Int Wound J 4:256-269, 2007. 
9. Morykwas MJ, Simpson J, Punger K, et al: Vacuum-assisted closure: state of basic research and physiologic foundation. Plastic and reconstructive surgery 117:121S, 2006.

10. Chen SZ, Li J, Li XY, et al: Effects of vacuum-assisted closure on wound microcirculation: an experimental study. Asian J Surg 28:211-217, 2005.

11. Saxena V, Hwang CW, Huang S, et al: Vacuum-assisted closure: microdeformations of wounds and cell proliferation. Plast Reconstr Surg 114:1086-1096; discussion 1097-1088, 2004.

12. Scherer SS, Pietramaggiori G, Mathews JC, et al: The mechanism of action of the vacuum-assisted closure device. Plast Reconstr Surg 122:786-797, 2008.

13. McNulty AK, Schmidt M, Feeley T, et al: Effects of negative pressure wound therapy on fibroblast viability, chemotactic signaling, and proliferation in a provisional wound (fibrin) matrix. Wound Repair Regen 15:838-846, 2007.

14. Adkesson MJ, Travis EK, Weber MA, et al: Vacuum-assisted closure for treatment of a deep shell abscess and osteomyelitis in a tortoise. J Am Vet Med Assoc 231:1249-1254, 2007.

15. Ben-Amotz R, Lanz OI, Miller JM, et al: The use of vacuum-assisted closure therapy for the treatment of distal extremity wounds in 15 dogs. Vet Surg 36:684-690, 2007.

16. Demaria M, Stanley BJ, Hauptman JG, et al: Effects of negative pressure wound therapy on healing of open wounds in dogs. Vet Surg 40:658-669, 2011.

17. Guille AE, Tseng LW, Orsher RJ: Use of vacuum-assisted closure for management of a large skin wound in a cat. J Am Vet Med Assoc 230:1669-1673, 2007. 
18. Kirkby K, Wheeler J, Farese J, et al: Surgical views: vacuum-assisted wound closure: clinical applications. Compendium (Yardley, PA) 32:E1, 2010.

19. Kirkby KA, CCRT D, Wheeler JL, et al: Vacuum-assisted wound closure: application and mechanism of action. Compend Contin Edu Vet 31:578-576, 2009.

20. Lafortune M, Fleming GJ, Wheeler JL, et al: Wound management in a juvenile tiger (Panthera tigris) with vacuum-assisted closure (V.A.C. Therapy). J Zoo Wildl Med 38:341-344, 2007.

21. Owen L, Hotston-Moore A, Holt P: Vacuum-assisted wound closure following urineinduced skin and thigh muscle necrosis in a cat. Vet Comp Orthop Traumatol 22:417-421, 2009. 


\section{Negative Pressure Wound therapy (NPWT): Evolution, Pathophysiology,}

Indications, Contraindications and Complications, and Application in Veterinary Medicine

Part II.a. Development of Negative Pressure in Wound Therapy

Over ten years ago, Fleischmann and Morykwas introduced the concept of applying subatmospheric pressure to wounds in order to promote rapid granulation and tissue healing. ${ }^{1,2}$ The NPWT device was initially investigated in the United States at Wake Forest University and was then further developed by KCI technology. The US FDA approved the NPWT device and its use for wound therapy in $1995 .{ }^{3}$ NPWT has gradually become recognized by different synonyms: vacuum assisted closure (VAC), topical negative pressure (TNP), sub-atmospheric pressure (SAP), vacuum sealing technique (VST), and sealed surface wound suction (SSS). ${ }^{3,4}$ Although there are many recognized names, the concept and technique is the same.

Prior to the initial studies performed by Morykwas in the United States, Fleishmann reported clinical outcomes of vacuum assisted wound closure in 121 patients in Europe. ${ }^{1}$ The major benefit outlined in this report was the controlled closed environment created by "sealing" the open wound during the healing process. Fleishmann claimed that sealing the wound protected it from environmental contaminations and secondarily he claimed, the vacuum removed deleterious exudate, improving healing. ${ }^{1}$ Thereafter, NPWT was developed in order to improve healing by second intention and was either used as a complimentary therapy prior to surgery or in the place of surgery for debilitated patients. ${ }^{2,5}$ Wounds that heal by second intention 
require contraction, neovascularization, granulation tissue formation, and epithelialization. ${ }^{2}$ NPWT seemed to improve wound healing in these aspects.

The NPWT system employs a medical grade open cell foam or gauze dressing, with varying sized pores, which is cut to size and placed directly on the wound. ${ }^{1,2,4-6}$ The dressing is then directly sealed with a non-permeable adhesive drape which also encompasses about 3-5 cm of surrounding intact skin in order to facilitate a vacuum. The evacuation device is a non-collapsible tube which is either embedded in the foam and sealing drape or is attached to a flat perforated disk which is placed over a small hole in the non-permeable drape..$^{2,4,5,7}$ The evacuation tube is then attached to an adjustable vacuum pump allowing settings for subatmospheric pressure and a collection canister. $^{1,2,4,5}$ Research with NPWT was first focused on wound blood flow, granulation tissue formation, cycle of negative pressure application, and skin flap survival. ${ }^{2,5,8}$

\section{Part II.b. Wound Filler}

After the initial description of NPWT used polyvinyl alcohol and polyurethane ether foam as the primary wound fillers, questions were raised as to if the specific foam or other wound fillers would change the desired local effect on the treated wound. ${ }^{1,2,5}$ Current literature reports an increase in blood flow, angiogenesis, cellular microdeformation and development of granulation tissue despite the wound filler chosen. $^{9-12}$ Therefore the wound filler choice is often decided based on preference and practicality.

Fleischmann first described vacuum sealing of wounds with polyvinyl alcohol foam (PVA) dressing. ${ }^{1}$ It was hypothesized that PVA dressing may provide a 
microenvironment for manipulating T-cell mediated immune responses for wound healing, after populations of T, B and natural killer lymphocytes were found in the foam after being applied to a wound. ${ }^{13}$ Unfortunately, this study did not compare inflammatory responses of wounds treated with other wound fillers or without NPWT. PVA is a hydrophilic foam dressing with a pore size of $60-270 \mu \mathrm{m}$ which is reported to reduce proliferative tissue ingrowth to the dressing. ${ }^{6,14}$ The foam is pre-moistened with sterile water and is reported to cause less pain and irritation when compared to polyurethane ether foam dressings. ${ }^{6}$ With negative pressure settings of $125 \mathrm{mmHg}$, PVA increases cutaneous blood flow 2 fold when compared to controls. Furthermore, optimal cutaneous blood flow is seen with negative pressure settings of $250-350 \mathrm{mmHg}$ when using PVA. ${ }^{6}$ It is suggested that PVA promotes smooth, thin and strong granulation tissue formation, and is reported to be easily molded to awkwardly shaped wounds. ${ }^{15}$ In patients with exuberant or rapid granulation tissue formation, such as young children, PVA dressings are recommended by the manufacturer. Other manufacturer indications for this dressing include protecting delicate tissue or to promote graft take. ${ }^{16}$ PVA was suggested as a potential NPWT dressing for delayed closure after abdominal surgery, but the technique with PVA is not yet described at the time of writing this report. ${ }^{3}$ This foam dressing is not as well documented in the literature as cotton gauze or polyurethane ether foam dressings with NPWT. ${ }^{11,12,17-20}$

Polyurethane ether (PU) foam is the most commonly used wound filler which is a hydrophobic dressing with pore size ranging from $400-600 \mu \mathrm{m} .^{2,5,6}$ This is an ideal foam dressing for fibrovascular tissue ingrowth which is reported to be greatest when pore size is around $500 \mu \mathrm{m} .{ }^{21}$ The benefits of increased blood flow, faster appearance of 
granulation tissue, improved skin flap survival, and bacterial clearance seen with NPWT are reported in experimental studies using PU foam as wound fillers. ${ }^{2,5}$ After the initial reports with wounds and skin grafts, PU foam with a perforated nonadherent polyethene sheet protecting abdominal viscera was reported for the management of open abdomen surgery and treatment of enterocutaneous fistulas. ${ }^{22,23}$ Negative pressure applied to PU foam at $125 \mathrm{mmHg}$ increases cutaneous blood flow 4 fold compared to controls and 2 fold compared to PVA foam at the same negative pressure setting. ${ }^{6}$ Recently, more studies are comparing PU foam to gauze dressings for NPWT. ${ }^{9-12,18,24}$ PU foam with NPWT results in an overrepresentation in the inflammatory pathway by increasing cytokine, interleukin, and platelet derived growth factor (PDGF) signaling pathways when compared to gauze under pressure. $^{24,25}$ Additionally, the overrepresentation of inflammatory signaling pathways is complimented by an increase in anti-inflammatory genes, such as suppressors of cytokine signaling 3 and 4 and IL-10 that modulate inflammation. ${ }^{24}$ PU foam also shows enhanced gene signaling in pathways important for the proliferative phase of wound healing, such as the Rho-GTPase and integrin signaling pathways when compared to gauze under pressure. ${ }^{24}$ In an in vitro study by McNulty, PU foam was shown to have a significant effect on cell response following NPWT which changed fibroblast morphology, decreased cell fibroblast apoptosis, and increased chemotactic signaling compared to gauze under the same subatmospheric pressure setting. ${ }^{26}$ This study revealed that fibroblast cell bodies exposed to PU foam and negative pressure were thicker and spaced farther which differed considerably from the static fibroblasts which were thin and showed a dendritic morphology with elongate extensions. ${ }^{26}$ Furthermore, after staining viable mitochondria within fibroblasts, median 
cell death in the gauze under suction culture group was 11.7 fold higher than for static cultures which were not significantly different then the cultures treated with negative pressure and PU foam. ${ }^{26}$ As an indicator of oxidative phosphorylation capacity, this same group found cytochrome c oxidase quantity was $30 \%$ higher when using NPWT with PU foam when compared to NPWT with gauze. ${ }^{25}$ Furthermore, markers of cellular respiration such as ATP/ADP ratio and energy charge were significantly increased after 48 hours of treatment with NPWT and foam compared to gauze and static conditions in this in vitro study. ${ }^{25}$ Finally in this in vitro study, wound healing proteins, transforming growth factor (TGF) $\beta$ and PDGF ( $\alpha$ and $\beta$ ), were found to be higher than gauze under pressure or static controls. ${ }^{25}$ Other studies reported that there is no difference in pressure transduction applied to the wound when PU foam or gauze is used as the wound filler for negative pressure. ${ }^{18,19} \mathrm{PU}$ foam when compared to gauze under pressure can increase wound contraction, but some of the negative qualities associated with PU foam when compared to gauze include decreased blood flow from the periphery of wounds, increased damage to underlying viscera when used for sternotomy wounds, and increased inflammatory and pain associated neuropeptides..$^{9,11,12,17-19,27}$ Techniques for decreasing pain associated with foam bandage changes have included interface dressings such as petrolatum impregnated gauze or silicone dressings applied between the wound and wound filler as a contact layer, but these contact layers decrease the pressure at the wound surface below the set pressure. ${ }^{28}$ Manufacturers have developed PU foam dressings that are micro-bonded with metallic silver which has resulted in a $99.9 \%$ microorganism kill within the first thirty minutes in vitro. ${ }^{29,30}$ Exposure of this silver foam dressing results in oxidation of metallic silver to ionic silver, allowing continued 
release of silver ions. ${ }^{30}$ Silver exerts its antibacterial properties by inhibiting cellular respiration, denaturing nucleic acids, and altering cellular membrane permeability. ${ }^{30,31}$ Furthermore, a green polyurethane foam dressing was developed in order to facilitate monitoring of the wound exudate and hemorrhage. This foam has the same mechanical properties as the black polyurethane foam although it is reported to have a higher tensile strength. $^{27}$

Gauze used as a wound filler has gained popularity in the literature due to the continued positive wound healing properties seen with NPWT in addition to evidence that bandage changes with gauze may be less painful then with foam dressings. ${ }^{11,15,17,18}$ NPWT with gauze caused similar undulations and cellular microdeformation as compared to NPWT with PU foam. ${ }^{10}$ Despite the similar microdeformation seen with gauze wound filler, the wound tissue does not have the same degree of tissue ingrowth and haphazard tissue disorganization which may contribute to more uncomfortable bandages changes seen with foam as a wound filler. ${ }^{32}$ Calcitonin gene-related peptide and substance $\mathrm{P}$ neuropeptides, which are known to signal pain, are almost doubled in the negative pressure treated wounds with foam as compared to the negative pressure treated wounds with gauze. ${ }^{17}$ Suggestions have been made that gauze should be used as a wound filler when thick granulation tissue is not wanted or when there is cosmetic concern. ${ }^{17,32,33}$ Whether or not the gauze dressing causes comparable wound contraction in the first week of healing to PU foam is under debate with contradicting results. ${ }^{10,24}$ Polyhexamethaline biguanide impregnated gauze was shown to inhibit growth in vitro of Micrococcus lutea, Staphylococcus intermedius, Staphylococcus schleiferi ss. schleiferi, Enterococcus faecium, Escherichia coli, and Enterobacter aerogenes. ${ }^{34}$ Although clinical studies have 
utilized silver and antimicrobial products as contact layers under gauze with negative pressure, there is a lack of studies comparing wound bacterial burden in wounds treated with antimicrobial impregnated gauze compared to bacterial burden in wounds treated with traditional gauze and NPWT. ${ }^{33}$ Due to differing nature of granulation tissue formation between foam and gauze dressings with NPWT, recent studies have also investigated the effects of mesh as a wound filler. ${ }^{35}$ Mesh performed similarly to gauze dressings in ease of dressing removal and in wound microdeformation. In regards to granulation tissue formation, mesh dressings were superior then gauze dressings but inferior to foam in the formation of granulation tissue. ${ }^{35}$ Continued research with different wound fillers have permitted clinicians the capability to select which filler is appropriate based on the type of wound healing or granulation tissue desired.

\section{Part II.c. Negative Pressure Setting}

Pressure application can be applied at a wide range of negative pressure settings. The negative pressure therapy can be administered at lower or higher pressure settings depending on desired local effect. Additionally the mode of negative pressure application is varied between intermittent, continuous or variable pressure settings. ${ }^{11}$

The initial clinical cases using negative pressure for vacuum sealing of wounds, claimed accelerated wound healing, decreased wound edema, and increased bacterial clearance when negative pressures were applied at $600 \mathrm{mmHg}$ using PVA foam dressing. ${ }^{1}$ Varying levels of negative pressure application were then investigated to determine the optimal pressure setting. After applying pressure at $25 \mathrm{mmHg}$ increments from $0 \mathrm{mmHg}$ to $400 \mathrm{mmHg}$ while measuring blood flow, optimal blood flow was 
recorded at $125 \mathrm{mmHg}$ which was 4 times above the baseline blood flow with PU foam dressing. ${ }^{2}$ Blood flow was inhibited at pressure settings of $400 \mathrm{mmHg}$ and above but the distance of inhibited blood flow from the wound edge was not initially clearly defined. ${ }^{2}$ Microvascular blood flow is affected to varying degrees depending on the tissue type surrounding the wound (i.e subcutaneous tissue or muscle) after subatmospheric pressure is initiated. ${ }^{36}$ Negative pressure increases microvascular blood flow in tissues adjacent to wound edges and is further delineated to an area about a centimeter away from wounds in a porcine model. ${ }^{36}$ Furthermore, blood flow is increased in muscle but for a shorter distance from the wound edge as compared to subcutaneous tissue. Closer to the wound, negative pressure therapy induces hypoperfusion that increases in area with increasing subatmospheric pressure. ${ }^{36}$ Subcutaneous tissue seems to be more affected by hypoperfusion then muscular tissue. ${ }^{36}$ Lower pressure settings of around $75 \mathrm{mmHg}$ for subcutaneous or delicate tissue and slightly higher negative pressures for muscle of around 100-125 mmHg are recommended based on concern with tissue ischemia and hypoperfusion. ${ }^{36}$ Another group has recently repeated wound edge microvascular blood flow studies and found there was no statistically significant increase in blood flow $2.5 \mathrm{~cm}$ from the wound edge when comparing subatmospheric pressure of $80 \mathrm{mmHg}$ to 125 mmHg. ${ }^{37}$ There was a $90 \%$ and $100 \%$ increase in blood flow $2.5 \mathrm{~cm}$ from the wound edge with subatmospheric pressure settings of $80 \mathrm{mmHg}$ and $125 \mathrm{mmHg}$, respectively, in this study which was not statistically significant. In conjunction with the $97 \%$ and $100 \%$ decrease in blood flow $0.5 \mathrm{~cm}$ from the wound edge with subatmospheric pressures of 80 $\mathrm{mmHg}$ and $125 \mathrm{mmHg}$, respectively, the authors suggest that lower pressures may be used to achieve similar results to the traditional pressure setting. ${ }^{37}$ A recommendation to 
use higher subatmospheric pressure settings of $125 \mathrm{mmHg}$ for treatment of a highly exudative wound in the acute period was made by this group after another study revealed that this setting was the most efficacious in removing $100 \%$ of fluid infused to a surgically created wound. ${ }^{38}$ Both of these later porcine wound studies were performed with gauze under pressure unlike the blood flow study performed by Wackenfors which was performed with PU foam. ${ }^{36-38}$ The direct effect of wound circulation by NPWT is defined by Chen et al. ${ }^{39}$ Microcirculation of wounds treated with subatmospheric pressures between 75 and $150 \mathrm{mmHg}$, shows an increase in blood flow velocity within the wound capillaries with increasing subatmospheric pressure. Subatmospheric pressures greater than $112 \mathrm{mmHg}$ has a residual effect on microcirculatory velocity which remains higher than baseline measurements 20 minutes after treatment. ${ }^{39}$ Additionally, negative pressures of $112 \mathrm{mmHg}$ reveal an increased capillary density within the first week of treatment when compared to controls, and the mechanical forces exerted by negative pressure change endothelial morphology, stimulate endothelial proliferation, capillary budding and angiogenesis. ${ }^{39}$ In agreement with these findings, wounds that are treated with subatmospheric pressure of $125 \mathrm{mmHg}$ are completely filled with granulation tissue by eight days after creation, but wounds of the same size created on the same day, that are treated with subatmospheric pressures of $25 \mathrm{mmHg}$ and 500 mmHg, are only filled with $21 \%$ and $6 \%$ of granulation tissue, respectively. ${ }^{8}$

Negative pressure therapy is reported as beneficial adjunctive therapy for skin grafts and flaps by reducing edema formation, preventing shear forces, and decreasing hematoma formation while increasing the rate of granulation tissue formation. ${ }^{2,40-44}$ The negative pressure settings initially described for use over skin grafts/flaps were based on 
empirical recommendations, but recently investigations were performed in order to define the optimal pressure setting. The porcine study by Morykwas et al reveals that skin grafts that are treated with negative pressure four days prior to surgery as well as after graft surgery have the greatest survival percentage. ${ }^{2}$ Flaps were treated with subatmospheric pressure of $125 \mathrm{mmHg}$ on a continuous setting in this study. Although some authors make recommendations that subatmospheric pressure settings of only $50 \mathrm{mmHg}$ are needed to reduce edema over closed incisions or skin grafts, clinical cases report 95\% success rate with split thickness skin grafting when subatmospheric pressure between 75 and $125 \mathrm{mmHg}$ was applied. ${ }^{5,40,42,45}$ Blackburn reported that using negative pressure to bolster graft take was beneficial due to total immobilization of the graft, elimination of shear forces, decreased fluid accumulation and decreased bacterial contamination. ${ }^{43}$ In this report the negative pressure setting was set to $125 \mathrm{mmHg}$ and the author also reported there was decreased edema in rotated muscle flaps with improved contour conformity for irregular surfaces. ${ }^{43}$ In a case study where negative pressure was used to assist in securing penile skin grafts, the recommended subatmospheric pressure was 75 $\mathrm{mmHg}$ on a continuous cycle. ${ }^{46}$ In veterinary medicine, there was a case series of 8 dogs that utilized negative pressure over full thickness skin grafts in which the setting was reduced to $75 \mathrm{mmHg}$ over the graft site after a nonadherent, petrolatum impregnated gauze was placed as a wound contact layer under the foam. ${ }^{47}$ Successful graft take was witnessed in all of those cases. ${ }^{47}$ Another recent study in veterinary medicine, reported beneficial effects of graft adherence and decreased necrosis in full thickness skin grafts after applying $65 \mathrm{mmHg}$ of negative pressure in a continuous setting. ${ }^{48}$ In general, majority of the case reports for negative pressure settings over skin grafts are based on 
initial recommendations from Morykwas and Chen complimented by Wakenfors which reported increased blood flow within and surrounding the wound. ${ }^{2,36,39}$ Therefore, about 100 clinical cases of skin grafts treated with subatmospheric pressure of $100-125 \mathrm{mmHg}$ have a mean take of $95 \% .^{40-42,44,46}$ Although retrospective studies have shown a significant advantage of negative pressure treated skin grafts over traditional dressings, recommendations for subatmospheric pressure setting were made empirically with no prospective controlled studies dictating which is the ideal subatmospheric pressure for skin graft placement.

NPWT with laparostomy was reported for treatment of abdominal compartment syndrome, septic peritonitis, as a part of damage control surgeries after trauma, or when repeated re-entry into the peritoneal cavity was planned. ${ }^{49}$ Vacuum assisted closure of abdominal surgeries was reported as early as the 1990 's. ${ }^{49,50}$ The negative pressure setting most commonly used is $125 \mathrm{mmHg}$, although a range was reported from 50 $\mathrm{mmHg}$ to $150 \mathrm{mmHg}{ }^{49,51-53}$ Although complications are rare with this treatment modality, post laparostomy enterocutaneous fistula formation was a suggested complication due to increasing subatmospheric pressure application. ${ }^{22,54,55}$ A controlled microvascular intestinal study revealed that intestinal wall blood flow significantly was decreased after application of subatmospheric pressures between 50 and $170 \mathrm{mmHg}$, and the decreased blood flow escalated as the pressure was increased from 50 to $170 \mathrm{mmHg} .{ }^{55}$ In the same study, there was no significant difference in the blood flow to the omentum during negative pressure settings of 50 and $70 \mathrm{mmHg}$, but a significant decrease in omental blood flow was reported with pressures set between 100 and $170 \mathrm{mmHg} .{ }^{55}$ This same group further defined that decreased intestinal blood flow following vacuum 
assisted closure technique was most pronounced in the microvascular blood flow of the intestine directly in apposition with the foam dressing. ${ }^{22}$ The second intestinal loop that was in contact with the visceral protective layer in this study had a significant but less pronounced decrease in intestinal blood flow, and therefore the conclusion was made that effect on intestinal blood flow decreased with distance from the negative pressure source. ${ }^{22}$ Interestingly, decreasing negative pressure settings from $150 \mathrm{mmHg}$ to a lower setting of $50 \mathrm{mmHg}$ did not correlate with a change in subatmospheric pressure of the intestinal surface. ${ }^{56}$ In the same porcine study, peritoneal fluid evacuation was $95 \%$ and $125 \%$ of that experimentally infused after 10 minutes of subatmospheric pressure therapy set at $75 \mathrm{~mm} \mathrm{Hg}$ and $150 \mathrm{mmHg}$, respectively. ${ }^{56}$ Much like pressure settings applied over skin grafts, most pressure settings for vacuum assisted abdominal closure are selected based on empirical recommendations. Further prospective controlled studies are required to define the most ideal negative pressure setting for this use of vacuum assisted wound closure system.

In addition to the degree of subatmospheric pressure setting, the mode of subatmospheric pressure application is also able to be adjusted to a continuous, intermittent or variable setting. ${ }^{2,11}$ Morykwas' initial porcine investigation utilized two different modes of negative pressure application, continuous or intermittent. ${ }^{2}$ Rate of granulation tissue was deposited faster (103\% deposition) with intermittent subatmospheric pressure when compared to wounds exposed to continuous subatmospheric pressure (63\%). The increased rate of granulation tissue formation after intermittent therapy was attributed to repetitive release of intracellular secondary messengers, such as prostaglandins, inositol phosphates, protein kinase $\mathrm{C}$, and 
intracellular calcium. ${ }^{2}$ The messengers were ascribed to cause changes in expression of immediate-early genes, with subsequent matrix molecule synthesis and cell proliferation. ${ }^{2}$ Intermittent negative pressure was superior for epithelial migration and proliferation over a dermal substitute in an in vitro study when compared to continuous negative pressure and a control. ${ }^{57}$ Due to cycling and the changes in negative pressure with intermittent negative pressure therapy, the wound filler tends to expand and contract repeatedly over the wound and subsequent granulation tissue which has purportedly been painful to the patient. $^{5,11,58,59}$ Therefore the most common clinical setting for negative pressure is continuous. Clinical reports in veterinary medicine have only used continuous settings of subatmospheric pressure supposedly due to the tolerability of the animal and reports of discomfort in human medicine..$^{7,47,60-66}$ In order to relieve pain while seeing the benefit of improved healing reported with intermittent negative pressure, the concept of variable negative pressure was introduced. ${ }^{11,58,59}$ As opposed to intermittent negative pressure treatment which applies a set negative pressure to the wound in 5 minute intervals with 2 minutes in between cycles, variable negative pressure provides a smooth transition between two different levels of negative pressure (ex. $10 \mathrm{mmHg}$ and $80 \mathrm{mmHg}$ ) which thereby maintains the negative pressure environment throughout therapy. ${ }^{2,11}$ It is hypothesized that intermittent cycling of negative pressure could cause the adhesive drape to detach from the surrounding skin, and another proposed benefit to variable over intermittent negative pressure therapy is that negative pressure would never cease and therefore the subatmospheric force on the adhesive drape would never be lost, thus decreasing the risk of detachment. ${ }^{59}$ Variable negative pressure wound therapy performed equally to intermittent negative pressure wound therapy when the two were 
compared in a porcine wound model..$^{59}$ The blood flow decreased $0.5 \mathrm{~cm}$ from the wound edge comparably between the two treatment regimes, and blood flow increased consistently $2.5 \mathrm{~cm}$ from the wound edge for both groups as expected based on previous studies. ${ }^{36,37,59}$ The differences in surrounding tissue blood flow were less pronounced when there was a small difference between high and low pressure settings. ${ }^{59}$ Furthermore, this same group examined the effect on wound contraction, granulation tissue formation, and different wound fillers after variable, intermittent, or continuous negative pressure application. ${ }^{11}$ As expected, wounds treated with continuous negative pressure contracted immediately, but did not have as much contraction by the end of the study as compared to the intermittent or variable negative pressure treated wounds. ${ }^{11}$ In agreement with Morykwas' original study, granulation tissue was more pronounced in the wounds treated with intermittent and variable negative pressure therapy, and additionally was thicker, more irregular yet ingrown when foam was used as the wound filler as compared to gauze. ${ }^{11}$ Although the authors claimed that variable negative pressure was less painful, there are no reports of this modality being used clinically or research to support that variable negative pressure treatment is more tolerable at this time.

\section{Part II.d. Physiology of Negative Pressure in Wound Healing} After Fleischmann and Morykwas described the beneficial effects of negative pressure wound healing, numerous articles and groups have published reports on various aspects of NPWT, and yet the complexity of the effects of negative pressure on wound healing, is still not completely understood. ${ }^{1,2,5,67}$ The basic science and foundation of negative pressure that originated with Morykwas' work included manipulation of wound 
edema, blood flow, microdeformation, bacterial clearance and biochemical effects on wounds. More recently, some authors advocate that negative pressure benefits wound healing mainly by two mechanisms: tissue strain and stimulation of tissue mitogenesis, and the mechanical evacuation of interstitial fluid or edema. ${ }^{68}$

Reduction in interstitial fluid or wound edema is one of the most commonly reported mechanisms of action of NPWT. ${ }^{1,2,67-70}$ Initially, Morykwas inferred that negative pressure application evacuated wound edema and further increased the interstitial fluid gradient by decreasing interstitial hydrostatic pressure. ${ }^{2,67,70,71}$ The removal of edema decreased the diffusion distances as capillary pressure was then greater than interstitial pressure which allowed for improved perfusion and subsequent oxygenation. ${ }^{2,67}$ A decrease in wound edema was noted in a clinical report of a burn victim in which wounds resolved without additional reconstructive surgery after application of negative pressure, but this report did not define the mechanism of how wound edema decreased. ${ }^{72}$ It was postulated in a swine study of partial thickness burns, the decrease in cell death seen in the group treated with NPWT, when compared to the control group, was possibly due to decrease of interstitial fluid within the "zone of stasis" preventing the irreversible cellular death seen in the "zone of coagulation". ${ }^{67,71-73}$ Yang et al. described 68 patients with compartment syndrome and subsequent treatment by fasciotomy. Half of the cases treated vacuum assisted closure (VAC) resulted in faster wound closure when compared to the other half of the patients that were not treated with VAC therapy. Their theoretical conclusion was that the VAC assisted in reduction in wound edema and resolution of swelling. ${ }^{74}$ Although it is generally accepted that VAC 
therapy improves wound healing through its removal of wound edema, quantitative assessment is difficult and continued research is needed in this area.

Increase in wound perfusion is another claimed mechanism by which VAC therapy improves wound healing. Using an in vivo laser Doppler, Morykwas reported a fourfold increase in wound perfusion after treatment with negative pressure of 125 mmHg. ${ }^{2}$ This same study reported that greater negative pressures of $400 \mathrm{mmHg}$ decreased blood flow. Following this study, additional Doppler studies were performed to measure the effect of negative pressure on cutaneous blood flow. ${ }^{6}$ In one study, cutaneous blood flow was increased fivefold and about threefold from baseline when using PU and PVA foams respectively. ${ }^{6}$ This increase in wound blood flow was further defined by Chen et al. who concluded that negative pressure increased blood flow by increasing capillary caliber and density in addition to angiogenesis. ${ }^{39}$ Increased angiogenesis, capillary budding, and endothelial proliferation was attributed to mechanical forces, change in endothelial morphology and increase in blood flow in that study. Additionally, the wound capillaries went from being flat to rounded and dilated after ten minutes of negative pressure treatment, and after 30 minutes of negative pressure, capillary buds and villous processes were seen on the medial surfaces of the capillaries. Erythrocytes were noted within those capillaries within two hours whereas the wound capillaries in the control group treated without negative pressure were irregular with stenosis and no capillary budding 24 hours after treatment. ${ }^{39}$ In accordance with this study, Jacobs et al. found that negative pressure treated wounds had increased vessel densities, and as wound healing progressed the vessels became larger caliber, mature blood vessels when compared to wounds treated without negative pressure. ${ }^{75}$ 
This study also found the negative pressure treated wounds had an increase in expression of fibroblast growth factor (FGF-2) and vascular endothelial growth factor (VEGF) which are potent stimulators of angiogenesis. ${ }^{75}$ Negative pressure does not only have effect on perfusion within the wound but adjacent to the wound as well. The effects of negative pressure on blood flow $0.5 \mathrm{~cm}-4.5 \mathrm{~cm}$ from the wound edge in muscle and subcutaneous tissue was described by Wackenfors et al. ${ }^{36}$ Closer to the wound, VAC therapy induced hypoperfusion that became more pronounced with increasing negative pressure. It was also concluded that subcutaneous tissue was more vulnerable to hypoperfusion then muscle. ${ }^{36}$ There was an increase in blood flow a few centimeters away from the wound edge which was tissue dependent, but the increase in blood flow remained $40-50 \%$ above baseline for 10 minutes after negative pressure ceased. "Reactive hyperemia" was attributed to prolonged increase in blood flow after therapy. ${ }^{36}$ These results were consistently repeated in recent similar studies. ${ }^{37,76}$ Laser Doppler $^{3}$ which was used in the previously referenced studies was criticized in a controversial report by Kairinos. ${ }^{77}$ This study found a decrease in perfusion below negative pressure wound therapy dressings as dictated by pertechnetate radioisotope imaging. ${ }^{77}$ This group suggested that stimulation of angiogenesis within the wound was due to local hypoxia and shear stress created by the pressure on the wound. ${ }^{78}$ These contradicting studies highlight the fact that despite many accepted theories, the true mechanism of action of negative pressure wound therapy remains unknown.

Cellular proliferation after application of tension stress effect is a biologically proven phenomenon, and is considered one of the mechanisms of action for NPWT. ${ }^{79-81}$ This concept of cellular proliferation through tension stress was made popular by 
Ilizarov's work with distraction osteogenesis and limb lengthening. ${ }^{80,81}$ In one of Ilizarov's studies that described rigidity of bone fragment fixation with investigation into the rate and rhythm of distraction, changes in the cellular elements of the skin and soft tissue were also noted. ${ }^{81}$ In this study, tension stress induced dramatic changes in the basal layer of the skin which showed increased mitotic figures and increase in the basal cell layers. It was then concluded that skin and soft tissue cellular activity was activated by tension stress and gradual distraction could be used to create redundant skin. ${ }^{81}$ Cellular mechanisms that may be triggered by external mechanical loading were reviewed by Silver et al. ${ }^{82}$ Correspondingly, Morykwas alluded that application of subatmospheric pressure changed external forces and interrupted the integrin bridges and cytoskeleton, which caused release of intracellular second messengers like prostaglandins and inositol phosphates. Furthermore he attributed cellular proliferation to this phenomenon although his study did not actually investigate cellular deformation cause by subatmospheric pressure. ${ }^{2}$ Cellular proliferation was attributed to activation of signaling pathways (including protein kinases and $\mathrm{G}$ proteins), activation of stretch-activated ion channels (Calcium channels), and modulation of cell cytoskeleton. It was concluded that forces at the extracellular matrix level may additionally lead to increased growth factorlike activities that impact cellular proliferation and protein synthesis. ${ }^{82}$ This force could play a role in stretching of keratinocytes and subsequent cellular proliferation, DNA and protein synthesis. ${ }^{82}$ Microdeformation was investigated with NPWT by Saxena et al. in a computer (finite element) model. ${ }^{79}$ Negative pressure applied between 70 and 150 mmHg induced an average tissue strains between 5 and $20 \%$. This strain is consistent with the strain shown to promote cellular proliferation in vitro. ${ }^{79}$ After using a rat wound 
model with PU foam and NPWT, Ki67, a marker for actively replicating cells, was elevated in the group treated with negative pressure, which led to the conclusion that NPWT induced the highest cell proliferation rates with up to $83 \% \mathrm{Ki} 67$-positive nuclei. ${ }^{83}$ Chen et al. showed that these tensile forces may also play a role in the endotheliocyte proliferation of the wound capillaries. ${ }^{39}$ Some believe that there are two main theories for the mechanism of action of subatmospheric pressure on wounds: microdeformation and secondary tissue strain, and the mechanical evacuation of interstitial fluid or edema. $^{68,71}$ Prominence seems to be shifted towards mechanical properties of subatmospheric pressure which activates the vascular endothelial cell growth factor (VEGF) pathway, including factors such as extracellular regulated kinase (ERK) and Jun N-terminal protein kinase (JNK). ${ }^{68,71}$ After 5 days of negative pressure therapy, maximum increase in VEGF and FGF-2 was $40 \%$ and $140 \%$ higher when compared to control wounds in a recent study. ${ }^{75}$ This study suggested that because wound healing is complex with multiple different variables that need to be optimized, such as epithelialization, angiogenesis, granulation tissue formation, and wound contraction, a treatment modality that optimizes wound healing must not just affect one aspect of wound healing. ${ }^{75}$ Lastly, cellular microdeformation was implicated to be the cause of increased vascular density and decrease in matrix metalloproteinase activity within the wounds treated with negative pressure under foam contact. This was a plausible conclusion because the control wounds were not placed under the "microdeformational wound therapy" with negative pressure but were treated without foam contact. ${ }^{84}$

Investigations of NPWT and its effects on wounds have revealed multiple biochemical alterations that promote wound healing. Changes in the inflammatory 
response of wounds are evident after negative pressure application. ${ }^{67,85-87}$ In a swine wound study, there was a faster and higher increase in systemic anti-inflammatory cytokine, IL-10, during the first 4 hours of treatment with negative pressure therapy when compared to the control group treated with saline moistened gauze. ${ }^{87}$ In this same study, there were no changes in systemic proinflammatory cytokines, IL-6 and IL-8, or transforming growth factor- $\beta 1$ (TGF- $\beta 1) .{ }^{87}$ It was therefore proposed that the increases in systemic levels of immunosuppressive IL-10 and the absence of a decrease in systemic level of IL-6 may be one explanation why negative pressure was successful in simultaneously combating inflammation and promoting granulation tissue. ${ }^{87}$ To better define the action of negative pressure on local cytokine response, a prospective clinical study was performed including 32 patients with traumatic soft tissue injuries either treated with VAC or a non-medicated wound dressing. ${ }^{86}$ Mean of wound fluid IL-8 and VEGF were statistically higher during VAC therapy when compared to control wound dressings, but there was no statistically significant different in the IL-6 and FGF-2 of the respective wound fluids. ${ }^{86}$ The elevation in VEGF was reiterated with higher immunohistochemistry expression in the wound tissue. Immunohistochemistry also revealed an increase in neovascularization as evident by staining for von Willebrand's factor (vWF) and CD31. ${ }^{86}$ The increase in the chemoattractant, IL-8, was postulated to be due to the increase in oxygen partial pressure of wound tissue. The increase in VEGF which was attributed to be the cause for increased neovascularization was accredited to mechanical stretch and increased number of neutrophils as seen by histologic samples. ${ }^{86}$ Wound inflammation was altered when negative pressure was applied to chronic pressure ulcers. ${ }^{85}$ Wound fluid analysis of patients with pressure ulcers treated with VAC 
revealed a statistically significant decrease in a potent proinflammatory cytokine, tumor necrosis factor- $\alpha$ (TNF- $\alpha)$, but no significant difference in IL-1 $\beta$, matrix metalloproteinase-2 (MMP-2), MMP-3, or tissue inhibitor of metalloproteinase-1 (TIMP1).$^{85}$ While this pilot study revealed only a decrease in TNF-a without a change in MMP activity, another study contradicted this finding when MMP-9, MMP-9/NGAL (neutrophil gelatinase-associated lipocalin), and MMP-2 activity were all decreased in wounds treated with negative pressure. ${ }^{84}$ The decrease in MMP activity was more pronounced in the second week of the treatment, which could partially explain the contradicting results of the previously mentioned study which only looked at MMP activity within the first week of treatment. ${ }^{84,85}$ Moues et al highlighted the complexity of chronic wounds and that although MMP activity is commonly believed to hinder wound healing, their activity in wound healing is not fully understood. Additionally, this study supported a decrease in MMP activity with lower MMP/TIMP in wounds treated negative pressure when compared to wounds treated with standard gauze dressing. ${ }^{88}$

Likewise, negative pressure therapy is associated with changes in cell energetics, oxidative phosphorylation, and gene expression. In an in vitro study using a fibroblast wound matrix, cytochrome $c$ oxidase, energy charge and ATP/ADP ratio were

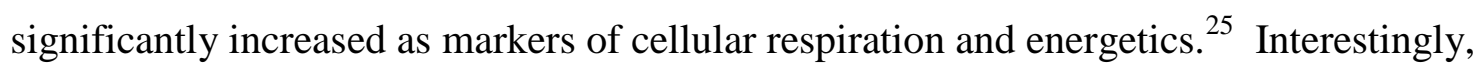
this study also found an increase in fibroblast culture growth factors, TGF- $\beta$ and PDGF, which are known to stimulate fibroblasts to synthesize collagen, glycosaminoglycans, and fibronectin, as well as decrease production of MMPs. ${ }^{25}$ Gene expression was defined in a wound healing study between three groups: negative pressure with foam, gauze under suction, and moist wound healing. Genes were determined to have $28 \%$ and $41 \%$ more 
expression in negative pressure treated wounds when compared to gauze under pressure and moist wound healing respectively. Genes for chemokine and cytokine signaling, integrin signaling, B-cell activation, interleukin signaling, PDGF signaling, Rho guanosine triphosphatase (Rho GTPase) cytoskeletal regulation, and angiogenesis were all significantly overrepresented in all study groups, but negative pressure with foam therapy had the most genes showing expression. ${ }^{24}$ Although there is a plethora of studies investigating the mechanisms and kinetics of wound healing seen with NPWT, the effects of NPWT are still largely unknown.

The effect of NPWT on wound bioburden is one of the more controversial mechanisms of action originally proposed by Fleischmann and Morykwas. ${ }^{1,2}$ Although Fleischmann hypothesized that wounds improved with vacuum sealing in his retrospective report partly due to a decrease in bacterial burden, evidentiary support was lacking. ${ }^{1}$ Morykwas created wound defects in pigs and injected $1 \mathrm{ml}$ of saline with $10^{8}$ organisms of either Staphylococcus aureus or Staphylococcus epidermidis. ${ }^{2}$ Biopsy samples were taken daily during negative pressure therapy bandage changes, and the number of organisms per gram of tissue decreased significantly between days 4 and $5 .^{2}$ The decrease in bacterial burden in these wounds was attributed to an increase in circulation and oxygenation to the wound and therefore enhanced resistance to infection and supplied oxygen necessary for neutrophilic oxidative bursts. ${ }^{2}$ Because NPWT bandages were changed daily, this finding of decreased bacterial burden was recently questioned. The decrease in wound bacterial burden was refuted in studies which performed NPWT bandage changes every 3-5 days. ${ }^{7,89}$ Despite this controversy, VAC therapy is used as an adjunctive treatment for infected wounds, chronic ulcers, incisional 
infections, traumatic wounds, open fractures and osteomyelitis with good clinical outcome. $^{90-93}$ In a prospective randomized study with trauma patients, an infection rate was significantly decreased in patients treated with NPWT as compared to a pressure dressing for treatment of draining hematomas, but there was no significant difference in infection rate for the patients with calcaneus, pilon, and high energy tibial plateau fractures. ${ }^{91}$ An additional prospective randomized clinical study found there was no difference in bacterial burden between patients with delayed surgical closure that were treated with NPWT or moist gauze therapy. ${ }^{94}$ In that study $42 \%$ of the NPWT group and $42 \%$ of the moist gauze treated group contained more than $10^{5}$ bacteria, and $48 \%$ of those patients healed without complication. NPWT tended to have a reduction in the number of nonfermentative Gram negative rods, and there also tended to have an increase in the number of Staphylococcus aureus. ${ }^{94}$ Despite these trends, there was no significant difference between the groups. ${ }^{94}$ NPWT decreased bacterial burden of Pseudomonas aeruginosa but not of Staphylococcus aureus in a complex wound model created on the left tibia of goats. ${ }^{95}$ The model was created to simulate an open tibial fracture and was injected with $1 \mathrm{ml}$ of greater than $10^{8}$ colony forming units of Pseudomonas aeruginosa or Staphylococcus aureus. Bacterial burden of NPWT and control "wet to dry" bandages was quantified by bacterial luminescence. ${ }^{95}$ On the other hand, some researchers have documented that in addition to a lack of a consistent decrease in bacterial burden, NPWT can actually cause an increase in bacterial burden. ${ }^{7,89,96}$ These controlled clinical studies in both human and veterinary medicine report continued wound healing in face of infection and therefore can't make a conclusion on the significance of the bacterial cultures with NPWT. ${ }^{7,89,96}$ Unduly, it is proposed that NPWT can alter wound 
environments promoting bacterial growth such as with anaerobic infections. This proposition emerged secondary to two case reports where patients developed either toxic shock syndrome secondary to a methicillin resistant Staphylococcus aureus, or anaerobic sepsis primarily due to Bacteroides while being treated with NPWT. ${ }^{97,98}$ With the advent of antibacterial or silver impregnated dressings, recent luminescent studies have documented a consistent decrease in wound bacterial burden after application of the impregnated wound dressings over an open fracture model with NPWT when compared to traditional wound dressings and NPWT. ${ }^{99}$ In lieu of contradicting reports regarding the effect of NPWT on bacterial burden, it is prudent to highlight the importance of other mechanisms by which NPWT promotes granulation tissue and wound healing and cautiously interpret the reports of decreased bacterial burden following NPWT.

Part II.e. Indications, Contraindications, and Complications

As it was discussed previously, the first development of NPWT was for treatment problematic, chronic wounds in debilitated patients or to improve second intention healing. ${ }^{2,3}$ Uses for NPWT have evolved to include treatment of traumatic wounds, wounds with exposed bone, wound complications following sternotomy, enterocutaneous fistula, burns, skin grafts and flaps, myoglobinuria, and adjunctive treatment for delayed abdominal closures. . $2,72,100-103$

Diabetic foot ulcers is one of the more problematic wound scenarios in which NPWT has improved healing times, patient comfort, and decreased the amount of limb amputations. $^{70,104}$ In acute wounds NPWT offers an alternative treatment for wounds that cannot be addressed by immediate primary closure, and additionally, can transform a 
large wound requiring complex reconstruction to a wound amenable to a more simple delayed primary or less extensive reconstructive surgery. ${ }^{1,3,90,105}$ In a clinical report of traumatic wounds with exposed bone, $95 \%$ of the patients had successful wound closure and none of the wounds required free tissue transfer. ${ }^{102}$ NPWT was applied after fasciotomies as adjunctive treatment for compartment syndrome after crushing injuries. ${ }^{45,74}$ In this application, NPWT allows for rapid time to fasciotomy closure in about 7 days as opposed to about 16 days without NPWT. ${ }^{74}$ Furthermore, crush injuries are associated with massive muscle trauma and rhabdomyolysis which can lead to myoglobinuria. ${ }^{3}$ After clinical absence of renal injury secondary to myoglobinuria in patients whose wounds were treated with NPWT, a prospective study was performed in rabbits after crush injuries. ${ }^{3,103}$ Treatment with fasciotomy and NPWT significantly decreased post injury systemic serum myoglobin levels over treatment with fasciotomies alone. ${ }^{103}$ This finding has introduced a new hypothesis about the effects of NPWT for management of severe crush injuries/compartment syndrome in human medicine. Human burn patients also present a complicated predicament for wound management. It is described that NPWT improves blood flow and removes edema in the "zone of stasis" in burn patients. In pigs with dermal burns, there was a decrease in the depth of cell death in as little as 6 hours after treatment with NPWT. ${ }^{73}$ Promising results continue to be reported in a prospective clinical trial with bilateral partial thickness hand burn patients. These patients were treated with NPWT or conventional dressings. ${ }^{106}$ The burns treated without negative pressure continued to show a decrease in blood flow to the burn wounds, whereas the NPWT seemed to prevent progression of the partial thickness burn wound by having similar blood flow before and after treatment. ${ }^{106}$ From the initial 
treatment of problematic non-healing ulcerative wounds to the application of NPWT to fasciotomy wounds, this treatment modality has evolved and is adapted for management of numerous types of acute and chronic wounds.

In addition to wound care, NPWT extends to be an adjunctive treatment for securing skin grafts, and is thought to be beneficial due to the decrease in shear forces after application, removal of wound exudate, and increase in neovascularization of the graft. $^{40,41,43}$ Initial porcine studies revealed that distal portions of all flaps that were treated prior to flap harvesting in addition to following surgery had the greatest percent survival as compared to the untreated control flaps. ${ }^{2}$ Comparative clinical studies also revealed a decrease in subsequent reconstructive surgeries when skin flaps were treated with negative pressure. ${ }^{41}$ Following these initial studies, recommendations were made for NPWT over skin grafts which include placing an interface dressing or using variable pressure settings. Reviewing clinical cases of skin grafts enhanced with NPWT utilizing an interface dressing, regardless of the mode of negative pressure setting or degree of negative pressure, graft success rate was about $95 \% .^{40-44}$ In addition to treating the flap or skin graft, Genecov et al. has shown that NPWT improves epithelialization of the skin graft donor site. ${ }^{100}$ Application for NPWT can play a beneficial role in intricate reconstructive procedures including free tissue transfer. In a recent prospective clinical study, increased intramuscular pressure and localized muscular compression, reduced ischemia and reperfusion injury induced inflammatory response, and reduced flap tissue interstitial edema, was shown in patients that had free tissue transfer and adjunctive treatment with NPWT. ${ }^{107}$ This led to the conclusion that NPWT had protective effects that could result in less tissue damage and apoptosis in muscle tissue. ${ }^{107}$ In veterinary 
medicine, a recent prospective controlled canine study, found that after full thickness mesh skin grafts were placed, grafts treated with NPWT had faster adherence, with improved production of granulation tissue within the mesh interstices and decreased necrosis when compared to the skin grafts treated without NPWT. ${ }^{48}$ Furthermore, literature supports the recommendation to use NPWT as adjunctive treatment of skin grafts, flaps, and donor sites to improve qualitative outcome, but additional evidence based research and recommendations are needed..$^{3,40-42,44,100,105,107}$

Abdominal surgery secondary to trauma and, further, increased abdominal pressure or visceral edema in human medicine may necessitate open abdominal management. ${ }^{105,108}$ This treatment technique is frowned upon by some due to high complication rate with bowel desiccation, frequent fistula formation, and infection leading to sepsis. ${ }^{108}$ Traditional methods for management of an open abdomen with temporary abdominal closure include the use of Bogotá bags, skin only closure, absorbable mesh, Wittmann pouch ${ }^{\mathrm{tm}}$, and Vacuum Assisted Closure ${ }^{\circledR} .^{23,101,108,109}$ The Vacuum assisted closure system, a type of negative pressure therapy, is reported to have certain advantages over other techniques for temporary abdominal closure. Namely, these advantages include: a decreased incidence of abdominal compartment syndrome, prevention of abdominal domain loss, abdominal wall preservation and fascial wound closure, management of hypothermia, collection and quantification of abdominal fluid loss, and effective delayed abdominal closure as compared with delayed closure planned with herniorraphies. ${ }^{23,105,108}$ It is recommended to change the VAC system for temporary abdominal closure every two days. Complications with temporary abdominal closure specifically consist of coagulopathies, hypothermia, ileus, loss of abdominal domain, 
infection, and enterocutaneous fistulas. ${ }^{108}$ Enterocutaneous fistulas can occur if bowel is exposed to air and desiccates, if the bowel surface/serosa is abraded by dressings, or by biomaterial adherence to the bowel. ${ }^{108}$ High output fistulas are challenging to treat and nonsurgical management is attractive. ${ }^{3}$ Because VAC techniques lead to an area of intestinal hypoperfusion or intestinal damage under the negative pressure interface, initially VAC techniques were considered contraindications for treatment of enterocutaneous fistulas. ${ }^{22,54,55}$ Intestinal zones of hypoperfusion instigated research with protective intestinal barriers such as fenestrated polyurethane films and paraffin gauze protection. $^{22,54,55}$ Despite intestinal hypoperfusion with negative pressure abdominal closure, cases of successful treatment of enterocutaneous fistulas with VAC techniques exist. ${ }^{110-113}$ Unfortunately, this application for negative pressure is still in its infancy and therefore defined recommendations for its use can be made after further investigations are performed.

In general, NPWT has few contraindications, and is a safe and efficacious treatment modality. Multiple research groups in addition to manufacturers of negative pressure wound systems have reported complications or contraindications of using NPWT. Some of these complications include infection, uncontrolled osteomyelitis, uncontrolled hemorrhage, malignancy, and pain. ${ }^{3,4,69,70}$ After a report of toxic shock syndrome and anaerobic sepsis during negative pressure wound treatment, recommendations for addressing infected or necrotic wounds or tissues were made including adequate surgical debridement and treatment prior to placement of the NPWT device. $^{30,97,98}$ Each bandage change is dictated by the specific wound and care needed. Broad guidelines report NPWT bandage changes anywhere from 2-3 days for wounds 
and up to 5 days when used for skin grafts, nevertheless as portrayed by DeFranzo et al. additional debridement maybe necessary at subsequent bandage changes. ${ }^{3,89,102}$ Along the same lines, untreated osteomyelitis is a contraindication for use of NPWT. ${ }^{30}$ Uncontrolled hemorrhage or coagulopathy is reported as another contraindication for negative pressure therapy, and additionally it is recommended that patients on anticoagulants should be monitored closely when treated with NPWT. ${ }^{4,45}$ Hemorrhage as a result of NPWT was reported sparsely in the literature. ${ }^{114-116}$ In a retrospective review of spinal infections treated with NPWT, two patients were attributed to have bleeding complications which resolved in one case after cessation of negative pressure. ${ }^{115}$ Furthermore, the recommendations to avoid placing foam dressing over an exposed artery or the cardiac silhouette stemmed from reports of vacuum assisted closure with resultant tibial arterial hemorrhage and right atrial rupture. ${ }^{114,116}$ These complications were multifactorial, but have led to precautionary recommendations when using NPWT in wounds with possible communication with major vessels or organs. Manufacturer recommendations also caution using negative pressure treatment in cases of malignancy, but these recommendations seem to be empirical without evidentiary support. ${ }^{3}$ Similarly, negative pressure was beneficial in increasing the rate of primary wound closure and decreasing amounts of surgery in patients that had removal of large musculoskeletal tumors as compared to controls that were not treated with negative pressure. ${ }^{117}$ Strategies to reduce pain and discomfort associated with negative pressure wound therapy have included applying lower pressure settings, changing foam dressings to gauze dressings or using PVA, and changing the mode of negative pressure from intermittent, to continuous, and, recently, to variable negative pressure settings. ${ }^{11,17,58}$ Although reported, 
complications are infrequent and seem to be avoidable with proper understanding of the reported literature.

\section{Part II.f. NPWT in Veterinary Medicine}

NPWT is in its infancy in veterinary medicine with majority of the available literature being clinical reports. ${ }^{61-66}$ Prior to the prospective experimental study which is the basis of this thesis, there were only three retrospective clinical case series and only two prospective, controlled experimental study involving NPWT. ${ }^{7,47,48,52,53}$ An initial case report involved successful management of a large traumatic skin wound in a cat which introduced the modality as a well-tolerated, easily applied wound management technique in the veterinary clinical setting. ${ }^{64}$ Thereafter a retrospective study reported 15 dogs with distal extremity wounds which were treated with NPWT in preparation for surgery and NPWT as adjunctive treatment for skin grafts. ${ }^{47}$ All cases had successful wound treatment with reconstructive surgical procedures with no complications associated with the NPWT. ${ }^{47}$ Further case reports using negative pressure therapy included patients with wounds secondary to: severe burns, radiation following injection site sarcoma removal, tortoise shell abscess and osteomyelitis, muscle and dermal necrosis after urine scalding, and a compromised superficial epigastric flap in a tiger. ${ }^{61-}$ 63,65,66 A prospective experimental wound study comparing NPWT to conventional wound dressings in dogs outlined pros and cons for using this treatment modality. ${ }^{7}$ Early appearance of granulation tissue, and smoother and less exuberant granulation tissue were some of the undisputed benefits concluded in this study. ${ }^{7}$ Interestingly, this study found that there was an increase in wound retraction without subsequent contraction in the 
NPWT group which was attributed to either the location of the study wounds or mechanical effects of the dressing holding the wound apart. ${ }^{7}$ Finally, there was no benefit of NPWT over control dressings in regards to increased bacterial clearance, which was consistent with some human controlled studies. ${ }^{7,89,94,96}$ The same group found no difference in bacterial burden between skin grafts treated with NPWT or control nonadherent bandages. ${ }^{48}$ NPWT application over full thickness mesh skin grafts in dogs had faster adherence of the graft, faster appearance of granulation tissue within the mesh of the graft, improved hair regrowth, and less necrosis as compared to the skin grafts treated with nonadherent dressings. ${ }^{48}$ The most recent development with NPWT use in veterinary medicine is its use for temporary abdominal closure in patients necessitating management with an open abdomen. ${ }^{52,53}$ Both of these reports describe a new technique for the negative pressure system to be used in temporary abdominal closure which was performed by partial closure of the external rectus sheath and skin over the caudal abdomen. The cranial third of the external rectus sheath was closed loosely and foam dressing was placed over this portion of the abdomen. Negative pressure was set to 125 mmHg continuously. ${ }^{52,53}$ This technique was admittedly different then reported techniques in human medicine where protective sheaths are utilized in order to protect the underlying viscera. ${ }^{22,52,54,56,101,109,113}$ The mortality rate in the study by Buote et al. was $50 \%$ being attributed to the poor prognosis associated with septic peritonitis, whereas Cioffi et al. claim that the low number of survivors seen in their study (3/8) needs to be substantiated with future studies. ${ }^{52,53}$ The therapeutic benefits in veterinary medicine seen with NPWT are starting to be appreciated in its diverse applications which derive from human medicine. This exciting and novel treatment modality is showing its 
beneficial role in veterinary medicine, and as the mechanisms of action are still being debated and are not fully understood, NPWT serves as a vast area of investigation in both human and veterinary medicine.

\section{Part II.g. References}

1. Fleischmann W, Becker U, Bischoff M, et al: Vacuum sealing: indication, technique, and results. European Journal of Orthopaedic Surgery \& Traumatology 5:37-40, 1995. 2. Morykwas MJ, Argenta LC, Shelton-Brown EI, et al: Vacuum-assisted closure: a new method for wound control and treatment: animal studies and basic foundation. Ann Plast Surg 38:553-562, 1997.

3. Plikaitis CM, Molnar JA: Subatmospheric pressure wound therapy and the vacuumassisted closure device: basic science and current clinical successes. Expert Rev Med Devices 3:175-184, 2006.

4. Lambert KV, Hayes P, McCarthy M: Vacuum assisted closure: a review of development and current applications. Eur J Vasc Endovasc Surg 29:219-226, 2005.

5. Argenta LC, Morykwas MJ: Vacuum-assisted closure: a new method for wound control and treatment: clinical experience. Ann Plast Surg 38:563-576; discussion 577, 1997.

6. Timmers MS, Le Cessie S, Banwell P, et al: The effects of varying degrees of pressure delivered by negative-pressure wound therapy on skin perfusion. Ann Plast Surg 55:665$671,2005$.

7. Demaria M, Stanley BJ, Hauptman JG, et al: Effects of negative pressure wound therapy on healing of open wounds in dogs. Vet Surg 40:658-669, 2011. 
8. Morykwas MJ, Faler BJ, Pearce DJ, et al: Effects of varying levels of subatmospheric pressure on the rate of granulation tissue formation in experimental wounds in swine. Ann Plast Surg 47:547-551, 2001.

9. Anesater E, Borgquist O, Hedstrom E, et al: The influence of different sizes and types of wound fillers on wound contraction and tissue pressure during negative pressure wound therapy. Int Wound J 8:336-342, 2011.

10. Borgquist O, Gustafsson L, Ingemansson R, et al: Micro- and macromechanical effects on the wound bed of negative pressure wound therapy using gauze and foam. Ann Plast Surg 64:789-793, 2010.

11. Malmsjo M, Gustafsson L, Lindstedt S, et al: The effects of variable, intermittent, and continuous negative pressure wound therapy, using foam or gauze, on wound contraction, granulation tissue formation, and ingrowth into the wound filler. Eplasty 12:e5, 2012.

12. Malmsjo M, Ingemansson R, Martin R, et al: Wound edge microvascular blood flow: effects of negative pressure wound therapy using gauze or polyurethane foam. Ann Plast Surg 63:676-681, 2009.

13. Gouttefangeas C, Eberle M, Ruck P, et al: Functional T lymphocytes infiltrate implanted polyvinyl alcohol foams during surgical wound closure therapy. Clin Exp Immunol 124:398-405, 2001.

14. Fleischmann W, Lang E, Russ M: [Treatment of infection by vacuum sealing]. Unfallchirurg 100:301-304, 1997.

15. Birke-Sorensen H, Malmsjo M, Rome P, et al: Evidence-based recommendations for negative pressure wound therapy: treatment variables (pressure levels, wound filler and 
contact layer)--steps towards an international consensus. J Plast Reconstr Aesthet Surg 64 Suppl:S1-16, 2011.

16. Contractor D, Amling J, Brandoli C, et al: Negative pressure wound therapy with reticulated open cell foam in children: an overview. J Orthop Trauma 22:S167-176, 2008. 17. Malmsjo M, Gustafsson L, Lindstedt S, et al: Negative pressure wound therapyassociated tissue trauma and pain: a controlled in vivo study comparing foam and gauze dressing removal by immunohistochemistry for substance $\mathrm{P}$ and calcitonin gene-related peptide in the wound edge. Ostomy Wound Manage 57:30-35, 2011.

18. Malmsjo M, Ingemansson R, Lindstedt S, et al: Comparison of bacteria and fungusbinding mesh, foam and gauze as fillers in negative pressure wound therapy - pressure transduction, wound edge contraction, microvascular blood flow and fluid retention. Int Wound J, 2012.

19. Malmsjo M, Ingemansson R, Martin R, et al: Negative-pressure wound therapy using gauze or open-cell polyurethane foam: similar early effects on pressure transduction and tissue contraction in an experimental porcine wound model. Wound Repair Regen 17:200-205, 2009.

20. Malmsjo M, Lindstedt S, Ingemansson R: Effects of foam or gauze on sternum wound contraction, distension and heart and lung damage during negative-pressure wound therapy of porcine sternotomy wounds. Interact Cardiovasc Thorac Surg 12:349$354,2011$.

21. Wake MC, Patrick CW, Jr., Mikos AG: Pore morphology effects on the fibrovascular tissue growth in porous polymer substrates. Cell Transplant 3:339-343, 1994. 
22. Lindstedt S, Hlebowicz J: Blood flow response in small intestinal loops at different depths during negative pressure wound therapy of the open abdomen. Int Wound J, 2012. 23. Miller PR, Thompson JT, Faler BJ, et al: Late fascial closure in lieu of ventral hernia: the next step in open abdomen management. J Trauma 53:843-849, 2002. 24. Derrick KL, Norbury K, Kieswetter K, et al: Comparative analysis of global gene expression profiles between diabetic rat wounds treated with vacuum-assisted closure therapy, moist wound healing or gauze under suction. Int Wound J 5:615-624, 2008. 25. McNulty AK, Schmidt M, Feeley T, et al: Effects of negative pressure wound therapy on cellular energetics in fibroblasts grown in a provisional wound (fibrin) matrix. Wound Repair Regen 17:192-199, 2009.

26. McNulty AK, Schmidt M, Feeley T, et al: Effects of negative pressure wound therapy on fibroblast viability, chemotactic signaling, and proliferation in a provisional wound (fibrin) matrix. Wound Repair Regen 15:838-846, 2007.

27. Malmsjo M, Ingemansson R: Effects of green foam, black foam and gauze on contraction, blood flow and pressure delivery to the wound bed in negative pressure wound therapy. J Plast Reconstr Aesthet Surg 64:e289-296, 2011.

28. Jones SM, Banwell PE, Shakespeare PG: Interface dressings influence the delivery of topical negative-pressure therapy. Plast Reconstr Surg 116:1023-1028, 2005.

29. Arce JM, Tatay AI, Luna ML, et al: [In vitro study of the antimicrobial properties of a silver ion-releasing polyurethane foam]. Cir Esp 89:532-538, 2011.

30. Gabriel A, Shores J, Bernstein B, et al: A clinical review of infected wound treatment with Vacuum Assisted Closure (V.A.C.) therapy: experience and case series. Int Wound J 6 Suppl 2:1-25, 2009. 
31. Ovington LG: The truth about silver. Ostomy Wound Manage 50:1S-10S, 2004.

32. Borgquist $\mathrm{O}$, Gustafson L, Ingemansson R, et al: Tissue Ingrowth Into Foam but Not Into Gauze During Negative Pressure Wound Therapy. Wounds-a Compendium of Clinical Research and Practice 21:302-309, 2009.

33. Chariker ME, Gerstle TL, Morrison CS: An algorithmic approach to the use of gauze-based negative-pressure wound therapy as a bridge to closure in pediatric extremity trauma. Plast Reconstr Surg 123:1510-1520, 2009.

34. Lee WR, Tobias KM, Bemis DA, et al: In vitro efficacy of a polyhexamethylene biguanide-impregnated gauze dressing against bacteria found in veterinary patients. Vet Surg 33:404-411, 2004.

35. Malmsjo M, Lindstedt S, Ingemansson R, et al: Use of bacteria- and fungus-binding mesh in negative pressure wound therapy provides significant granulation tissue without tissue ingrowth. Eplasty 14:e3, 2014.

36. Wackenfors A, Sjogren J, Gustafsson R, et al: Effects of vacuum-assisted closure therapy on inguinal wound edge microvascular blood flow. Wound Repair Regen 12:600606, 2004.

37. Borgquist O, Ingemansson R, Malmsjo M: Wound edge microvascular blood flow during negative-pressure wound therapy: examining the effects of pressures from -10 to 175 mmHg. Plast Reconstr Surg 125:502-509, 2010.

38. Borgquist $\mathrm{O}$, Ingemansson R, Malmsjo M: The influence of low and high pressure levels during negative-pressure wound therapy on wound contraction and fluid evacuation. Plast Reconstr Surg 127:551-559, 2011. 
39. Chen SZ, Li J, Li XY, et al: Effects of vacuum-assisted closure on wound microcirculation: an experimental study. Asian J Surg 28:211-217, 2005.

40. Azzopardi EA, Boyce DE, Dickson WA, et al: Application of topical negative pressure (vacuum-assisted closure) to split-thickness skin grafts: a structured evidencebased review. Ann Plast Surg 70:23-29, 2013.

41. Scherer LA, Shiver S, Chang M, et al: The vacuum assisted closure device: a method of securing skin grafts and improving graft survival. Arch Surg 137:930-933; discussion 933-934, 2002.

42. Dainty LA, Bosco JJ, McBroom JW, et al: Novel techniques to improve splitthickness skin graft viability during vulvo-vaginal reconstruction. Gynecol Oncol 97:949$952,2005$.

43. Blackburn JH, 2nd, Boemi L, Hall WW, et al: Negative-pressure dressings as a bolster for skin grafts. Ann Plast Surg 40:453-457, 1998.

44. Stetter C, Plaza T, von den Driesch P: Skin grafting of a chronic leg ulcer with combined Versajet-V.A.C. therapy. J Dtsch Dermatol Ges 4:739-742, 2006.

45. Webb LX: New techniques in wound management: vacuum-assisted wound closure. J Am Acad Orthop Surg 10:303-311, 2002.

46. Senchenkov A, Knoetgen J, Chrouser KL, et al: Application of vacuum-assisted closure dressing in penile skin graft reconstruction. Urology 67:416-419, 2006.

47. Ben-Amotz R, Lanz OI, Miller JM, et al: The use of vacuum-assisted closure therapy for the treatment of distal extremity wounds in 15 dogs. Vet Surg 36:684-690, 2007. 48. Stanley BJ, Pitt KA, Weder CD, et al: Effects of negative pressure wound therapy on healing of free full-thickness skin grafts in dogs. Vet Surg 42:511-522, 2013. 
49. Subramonia S, Pankhurst S, Rowlands BJ, et al: Vacuum-assisted closure of postoperative abdominal wounds: a prospective study. World J Surg 33:931-937, 2009. 50. Barker DE, Kaufman HJ, Smith LA, et al: Vacuum pack technique of temporary abdominal closure: a 7-year experience with 112 patients. J Trauma 48:201-206; discussion 206-207, 2000.

51. Perez D, Wildi S, Demartines N, et al: Prospective evaluation of vacuum-assisted closure in abdominal compartment syndrome and severe abdominal sepsis. J Am Coll Surg 205:586-592, 2007.

52. Cioffi KM, Schmiedt CW, Cornell KK, et al: Retrospective evaluation of vacuumassisted peritoneal drainage for the treatment of septic peritonitis in dogs and cats: 8 cases (2003-2010). J Vet Emerg Crit Care (San Antonio) 22:601-609, 2012.

53. Buote NJ, Havig ME: The use of vacuum-assisted closure in the management of septic peritonitis in six dogs. J Am Anim Hosp Assoc 48:164-171, 2012.

54. Lindstedt S, Hansson J, Hlebowicz J: Comparative study of the microvascular blood flow in the intestinal wall during conventional negative pressure wound therapy and negative pressure wound therapy using paraffin gauze over the intestines in laparostomy. Int Wound J 9:150-155, 2012.

55. Hlebowicz J, Hansson J, Lindstedt S: Microvascular blood flow response in the intestinal wall and the omentum during negative wound pressure therapy of the open abdomen. Int J Colorectal Dis 27:397-403, 2012.

56. Bjarnason T, Montgomery A, Hlebowicz J, et al: Pressure at the bowel surface during topical negative pressure therapy of the open abdomen: an experimental study in a porcine model. World J Surg 35:917-923, 2011. 
57. Baldwin C, Potter M, Clayton E, et al: Topical negative pressure stimulates endothelial migration and proliferation: a suggested mechanism for improved integration of Integra. Ann Plast Surg 62:92-96, 2009.

58. Borgquist $\mathrm{O}$, Ingemansson R, Malmsjo M: Individualizing the use of negative pressure wound therapy for optimal wound healing: a focused review of the literature. Ostomy Wound Manage 57:44-54, 2011.

59. Borgquist $\mathrm{O}$, Ingemansson R, Malmsjo M: The effect of intermittent and variable negative pressure wound therapy on wound edge microvascular blood flow. Ostomy Wound Manage 56:60-67, 2010.

60. Kirkby KA, CCRT D, Wheeler JL, et al: Vacuum-assisted wound closure: application and mechanism of action. Compend Contin Edu Vet 31:578-576, 2009. 61. Mullally C, Carey K, Seshadri R: Use of a nanocrystalline silver dressing and vacuum-assisted closure in a severely burned dog. J Vet Emerg Crit Care (San Antonio) 20:456-463, 2010.

62. Adkesson MJ, Travis EK, Weber MA, et al: Vacuum-assisted closure for treatment of a deep shell abscess and osteomyelitis in a tortoise. J Am Vet Med Assoc 231:12491254, 2007.

63. Woods S, de Castro Marques AI, Renwick MG, et al: Nanocrystalline silver dressing and subatmospheric pressure therapy following neoadjuvant radiation therapy and surgical excision of a feline injection site sarcoma. J Feline Med Surg 14:214-218, 2012. 64. Guille AE, Tseng LW, Orsher RJ: Use of vacuum-assisted closure for management of a large skin wound in a cat. J Am Vet Med Assoc 230:1669-1673, 2007. 
65. Lafortune M, Fleming GJ, Wheeler JL, et al: Wound management in a juvenile tiger (Panthera tigris) with vacuum-assisted closure (V.A.C. Therapy). J Zoo Wildl Med 38:341-344, 2007.

66. Owen L, Hotston-Moore A, Holt P: Vacuum-assisted wound closure following urineinduced skin and thigh muscle necrosis in a cat. Vet Comp Orthop Traumatol 22:417421, 2009.

67. Wood BC, Molnar JA: Subatmospheric pressure therapy: basic science review. J Surg Orthop Adv 20:168-175, 2011.

68. Webb LX, Pape HC: Current thought regarding the mechanism of action of negative pressure wound therapy with reticulated open cell foam. J Orthop Trauma 22:S135-137, 2008.

69. Banwell PE: Topical negative pressure therapy in wound care. J Wound Care 8:7984, 1999.

70. Banwell PE, Musgrave M: Topical negative pressure therapy: mechanisms and indications. Int Wound J 1:95-106, 2004.

71. Morykwas MJ, Simpson J, Punger K, et al: Vacuum-assisted closure: state of basic research and physiologic foundation. Plastic and reconstructive surgery 117:121S, 2006. 72. Molnar JA, Simpson JL, Voignier DM, et al: Management of an acute thermal injury with subatmospheric pressure. J Burns Wounds 4:e5, 2005.

73. Morykwas MJ, David LR, Schneider AM, et al: Use of subatmospheric pressure to prevent progression of partial-thickness burns in a swine model. J Burn Care Rehabil 20:15-21, 1999. 
74. Yang CC, Chang DS, Webb LX: Vacuum-assisted closure for fasciotomy wounds following compartment syndrome of the leg. J Surg Orthop Adv 15:19-23, 2006.

75. Jacobs S, Simhaee DA, Marsano A, et al: Efficacy and mechanisms of vacuumassisted closure (VAC) therapy in promoting wound healing: a rodent model. J Plast Reconstr Aesthet Surg 62:1331-1338, 2009.

76. Borgquist O, Anesater E, Hedstrom E, et al: Measurements of wound edge microvascular blood flow during negative pressure wound therapy using thermodiffusion and transcutaneous and invasive laser Doppler velocimetry. Wound Repair Regen 19:727-733, 2011.

77. Kairinos N, Voogd AM, Botha PH, et al: Negative-pressure wound therapy II: negative-pressure wound therapy and increased perfusion. Just an illusion? Plast Reconstr Surg 123:601-612, 2009.

78. Kairinos N, Solomons M, Hudson DA: Negative-pressure wound therapy I: the paradox of negative-pressure wound therapy. Plast Reconstr Surg 123:589-598; discussion 599-600, 2009.

79. Saxena V, Hwang CW, Huang S, et al: Vacuum-assisted closure: microdeformations of wounds and cell proliferation. Plast Reconstr Surg 114:1086-1096; discussion 10971088, 2004.

80. Ilizarov GA: The tension-stress effect on the genesis and growth of tissues: Part II. The influence of the rate and frequency of distraction. Clin Orthop Relat Res:263-285, 1989. 
81. Ilizarov GA: The tension-stress effect on the genesis and growth of tissues. Part I. The influence of stability of fixation and soft-tissue preservation. Clin Orthop Relat Res:249-281, 1989.

82. Silver FH, Siperko LM, Seehra GP: Mechanobiology of force transduction in dermal tissue. Skin Res Technol 9:3-23, 2003.

83. Scherer SS, Pietramaggiori G, Mathews JC, et al: The mechanism of action of the vacuum-assisted closure device. Plast Reconstr Surg 122:786-797, 2008.

84. Greene AK, Puder M, Roy R, et al: Microdeformational wound therapy: effects on angiogenesis and matrix metalloproteinases in chronic wounds of 3 debilitated patients. Ann Plast Surg 56:418-422, 2006.

85. Stechmiller JK, Kilpadi DV, Childress B, et al: Effect of Vacuum-Assisted Closure Therapy on the expression of cytokines and proteases in wound fluid of adults with pressure ulcers. Wound Repair Regen 14:371-374, 2006.

86. Labler L, Rancan M, Mica L, et al: Vacuum-assisted closure therapy increases local interleukin-8 and vascular endothelial growth factor levels in traumatic wounds. J Trauma 66:749-757, 2009.

87. Kilpadi DV, Bower CE, Reade CC, et al: Effect of Vacuum Assisted Closure Therapy on early systemic cytokine levels in a swine model. Wound Repair Regen $14: 210-215,2006$.

88. Moues CM, van Toorenenbergen AW, Heule F, et al: The role of topical negative pressure in wound repair: expression of biochemical markers in wound fluid during wound healing. Wound Repair Regen 16:488-494, 2008. 
89. Weed T, Ratliff C, Drake DB: Quantifying bacterial bioburden during negative pressure wound therapy: does the wound VAC enhance bacterial clearance? Ann Plast Surg 52:276-279; discussion 279-280, 2004.

90. Mullner T, Mrkonjic L, Kwasny O, et al: The use of negative pressure to promote the healing of tissue defects: a clinical trial using the vacuum sealing technique. Br J Plast Surg 50:194-199, 1997.

91. Stannard JP, Robinson JT, Anderson ER, et al: Negative pressure wound therapy to treat hematomas and surgical incisions following high-energy trauma. J Trauma 60:13011306, 2006.

92. Blum ML, Esser M, Richardson M, et al: Negative pressure wound therapy reduces deep infection rate in open tibial fractures. J Orthop Trauma 26:499-505, 2012.

93. Hersh RE, Kaza AK, Long SM, et al: A technique for the treatment of sternal infections using the Vacuum Assisted Closure device. Heart Surg Forum 4:211-215, 2001.

94. Moues CM, Vos MC, van den Bemd GJ, et al: Bacterial load in relation to vacuumassisted closure wound therapy: a prospective randomized trial. Wound Repair Regen 12:11-17, 2004.

95. Lalliss SJ, Stinner DJ, Waterman SM, et al: Negative pressure wound therapy reduces pseudomonas wound contamination more than Staphylococcus aureus. J Orthop Trauma 24:598-602, 2010.

96. Braakenburg A, Obdeijn MC, Feitz R, et al: The clinical efficacy and cost effectiveness of the vacuum-assisted closure technique in the management of acute and 
chronic wounds: a randomized controlled trial. Plast Reconstr Surg 118:390-397; discussion 398-400, 2006.

97. Chester DL, Waters R: Adverse alteration of wound flora with topical negativepressure therapy: a case report. Br J Plast Surg 55:510-511, 2002.

98. Gwan-Nulla DN, Casal RS: Toxic shock syndrome associated with the use of the vacuum-assisted closure device. Ann Plast Surg 47:552-554, 2001.

99. Stinner DJ, Waterman SM, Masini BD, et al: Silver dressings augment the ability of negative pressure wound therapy to reduce bacteria in a contaminated open fracture model. J Trauma 71:S147-150, 2011.

100. Genecov DG, Schneider AM, Morykwas MJ, et al: A controlled subatmospheric pressure dressing increases the rate of skin graft donor site reepithelialization. Ann Plast Surg 40:219-225, 1998.

101. DeFranzo AJ, Pitzer K, Molnar JA, et al: Vacuum-assisted closure for defects of the abdominal wall. Plast Reconstr Surg 121:832-839, 2008.

102. DeFranzo AJ, Argenta LC, Marks MW, et al: The use of vacuum-assisted closure therapy for the treatment of lower-extremity wounds with exposed bone. Plast Reconstr Surg 108:1184-1191, 2001.

103. Morykwas MJ, Howell H, Bleyer AJ, et al: The effect of externally applied subatmospheric pressure on serum myoglobin levels after a prolonged crush/ischemia injury. J Trauma 53:537-540, 2002.

104. Armstrong DG, Andros G: Use of negative pressure wound therapy to help facilitate limb preservation. Int Wound J 9 Suppl 1:1-7, 2012. 
105. Bovill E, Banwell PE, Teot L, et al: Topical negative pressure wound therapy: a review of its role and guidelines for its use in the management of acute wounds. Int Wound J 5:511-529, 2008.

106. Kamolz LP, Andel H, Haslik W, et al: Use of subatmospheric pressure therapy to prevent burn wound progression in human: first experiences. Burns 30:253-258, 2004. 107. Eisenhardt SU, Schmidt Y, Thiele JR, et al: Negative pressure wound therapy reduces the ischaemia/reperfusion-associated inflammatory response in free muscle flaps. J Plast Reconstr Aesthet Surg 65:640-649, 2012.

108. Kaplan M: Managing the open abdomen. Ostomy Wound Manage 50:C2, 1-8, quiz 1p following 8, 2004.

109. Fitzgerald JE, Gupta S, Masterson S, et al: Laparostomy management using the ABThera open abdomen negative pressure therapy system in a grade IV open abdomen secondary to acute pancreatitis. Int Wound J, 2012.

110. Hyon SH, Martinez-Garbino JA, Benati ML, et al: Management of a high-output postoperative enterocutaneous fistula with a vacuum sealing method and continuous enteral nutrition. ASAIO J 46:511-514, 2000.

111. Cro C, George KJ, Donnelly J, et al: Vacuum assisted closure system in the management of enterocutaneous fistulae. Postgrad Med J 78:364-365, 2002.

112. Alvarez AA, Maxwell GL, Rodriguez GC: Vacuum-assisted closure for cutaneous gastrointestinal fistula management. Gynecol Oncol 80:413-416, 2001.

113. Erdmann D, Drye C, Heller L, et al: Abdominal wall defect and enterocutaneous fistula treatment with the Vacuum-Assisted Closure (V.A.C.) system. Plast Reconstr Surg 108:2066-2068, 2001. 
114. White RA, Miki RA, Kazmier P, et al: Vacuum-assisted closure complicated by erosion and hemorrhage of the anterior tibial artery. J Orthop Trauma 19:56-59, 2005. 115. Jones GA, Butler J, Lieberman I, et al: Negative-pressure wound therapy in the treatment of complex postoperative spinal wound infections: complications and lessons learned using vacuum-assisted closure. J Neurosurg Spine 6:407-411, 2007.

116. Sartipy U, Lockowandt U, Gabel J, et al: Cardiac rupture during vacuum-assisted closure therapy. Ann Thorac Surg 82:1110-1111, 2006.

117. Bickels J, Kollender Y, Wittig JC, et al: Vacuum-assisted wound closure after resection of musculoskeletal tumors. Clin Orthop Relat Res 441:346-350, 2005. 


\section{Liquid Chromatography Mass Spectrometry}

\section{Part III.a. Liquid Chromatography}

High Pressure Liquid Chromatography (HPLC) is a separation technique using columns of different polarity depending on the compound to analyze, therefore separating interfering substances, such as those found in biological matrices. ${ }^{1}$ A typical HPLC system includes an eluent reservoir, a pump delivering the mobile phase in a controlled flow rate, an autosampler, an analytical column, a detector, and a data capture system..$^{\underline{3}}$ The data is then analyzed by a computer.

The analytical column is often protected by a guard column to extend its lifetime. The column's packing material or stationary phase typically contains particles with a diameter of 1.8 to $5 \mu \mathrm{m}$ which allow for greater efficiency as opposed to early liquid chromatography. ${ }^{\underline{3}}$ The separation is based on differential partitioning between the mobile and stationary phases. A compound will travel through the column at the same rate as the mobile phase and will be unretained if it does not interact appreciably with the stationary phase. The volume of the mobile phase it takes for an unretained molecule to go through the column is called the void volume. ${ }^{2}$ The length of time it takes of a retained compound to go through the column is called the retention time and depends on its capacity factor, which measures the degree of partition between the stationary and the mobile phase. ${ }^{2}$ Depending on the type of stationary phase, different mechanisms allow the retention of compounds. In the case of normal phase columns, the hydroxyl group at the surface of the silica will interact with the polar groups of a molecule causing retention. Typically, highly lipophilic compounds will elute with organic solvent (i.e. $n$ hexane) and more polar compounds with the addition of a percentage of alcohol such as 
2-isopropyl alcohol. In the case of reverse phase columns (such as octadecyl or ODScoated silica) the lipophilic molecules will interact with the long carbon chain and be retained. $\stackrel{2}{ }$ They will be eluted by increasing the percentage of organic solvents such as acetonitrile or methanol. Hydrophilic Interaction Liquid Chromatography, a variant of normal phase was used for the separation of cefazolin from other compounds. HILIC uses hydrophilic stationary phases with reversed-phase type eluents. It is often a column of choice for the separation of polar compounds when a mass spectrometer is involved because it allows the elution with a high organic solvent content which gives better ionization. In order to ionize molecules without contaminating the ionization source, volatiles salts have to be used (i.e. acetic acid, formic acid, ammonium formate). ${ }^{10,11}$

\section{Part III.b. Mass Spectrometry}

Mass spectrometry was initially utilized as a qualitative tool in 1912 for structure elucidation in organic chemistry. ${ }^{-}$It can also provide quantitative information (molecular mass or concentration) on analyte molecules.

Mass spectrometers can be divided into three fundamental parts, namely the ionization source, the analyzer, and the detector. First, the analyte is introduced into the ionization source of the instrument where it is ionized (positively or negatively charged). The ions are extracted into the analyzer region of the mass spectrometer under high vacuum where they are separated according to their mass $(\mathrm{m})$-to-charge $(\mathrm{z}) \operatorname{ratios}(\mathrm{m} / \mathrm{z})$. The separated ions are detected and this signal sent to a data system where the $\mathrm{m} / \mathrm{z}$ ratios are stored together with their relative abundance for presentation in the format of an $\mathrm{m} / \mathrm{z}$ spectrum. 
Atmospheric-pressure chemical ionization (APCI) and electrospray ionization (ESI) are two commonly used ionization interfaces for LC-MS. ${ }^{3}$ In the case of cefazolin, an ESI source was used. ESI is a softer ionization technique than APCI because little fragmentation is produced and the pseudo molecular ion is always observed. ESI uses electrical energy to assist the transfer of ions from the solution into the gaseous phase before they are subjected to mass spectrometric analysis. Ionic species in solution can thus be analyzed by ESI-MS with increased sensitivity. ${ }^{10}$

In the clinical laboratory, a quadruple mass analyzer is the most commonly used and consists of an assembly of 4 parallel metal rods is kept at equal distance, each pair of opposite rods being connected electrically. When ions travel through a magnetic or electrical field, their movement is affected by their $\mathrm{m} / \mathrm{z}$ ratio and this is the main principle of separating ions in MS. Cefazolin, like many small molecules is quantified with a triple quadrupole mass analyzer. The analyte ion of interest (usually called the precursor ion) is mass-selected by the first quadrupole (Q1) and allowed to collide with a collision gas (usually argon) in a second RF-only quadrupole collision cell (Q2), where the precursor ions are activated by collision and undergo further fragmentation to generate the daughter ions which are monitored by a third quadrupole mass analyzer (Q3). This system is commonly denoted as "triple-quad" or "MS/MS" in the literature. The mode of data acquisition used for the quantification of cefazolin is called Multiple Reaction Monitoring (MRM). Both Q1 and Q3 are static for a pre-determined pair of precursor and product ions (they filter specific ions). This confers the highest specificity and sensitivity and is commonly used in ESI-MS/MS quantification procedures. 
Coupled with a high performance liquid chromatograph (HPLC) for molecular fractionation prior to mass spectrometric analysis, HPLC/ESI-MS has become a very powerful technique capable of analyzing both small and large molecules of various polarities in complex biological samples. Despite high molecular weights, polarity, and low volatility of many antibiotics which makes them less amenable to this analysis, mass spectrometry was used to provide considerable analytical information in antibiotic research. ${ }^{\underline{1}} \underline{3}$

\section{Part III.c. Analysis of cefazolin}

HPLC coupled to a mass spectrometry detector offers a fast, accurate, and reproducible method of detecting cefazolin with comparable results to microbiological

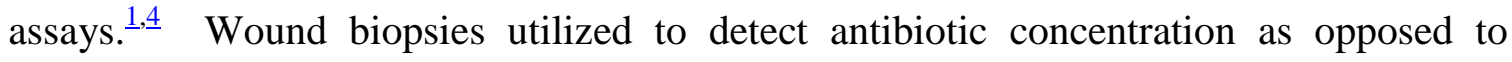
devices, such as an ultrafiltration sampling kit or microdialysis catheters, to measure the antibiotic concentration specifically in the interstitial fluid, have its disadvantages. $, \underline{5}, \underline{6}$ Homogenizing tissue biopsies combined the interstitial fluid, cells and subcellular organelles which can result in dilution and underestimation of the antibiotic concentration of cefazolin which is a compound mainly distributed extracellularly. ${ }^{6,7}$ In lieu of its limitations, tissue biopsies and liquid chromatography also has its benefits and can utilize a variety of detectors such as UV/Visible and mass spectrometric variants making this technique specific and sensitive and able to separate the molecule of interest in a biological matrix..$^{3}$ Liquid chromatography mass spectrometry was used as a tool in this Masters thesis, as previously described for the identification of beta-lactam antibiotics. ${ }^{.9}$ 
Samples extracts were purified by solid phase extraction. Cefazolin was separated from the other contaminants contained in plasma or tissues by HILIC chromatography and quantified by triple quad mass spectrometry. Ceftezole was the compound used as an internal standard as it is structurally related to cefazolin. Internal standards are important when performing quantitative measurements because of the variations in the ionization found in MS. $\frac{3}{}$ They are also used to calculate the recovery of the analyte of interest during the extraction and the clean-up processes (SPE). It this case, it was crucial to separate cefazolin and ceftezole chromatographically (different retention time) because they have the same daughter ion at $m / z$ 323.0. The separation was achieved by using acetonitrile-water (95:5) with $0.1 \%$ formic acid and $2 \mathrm{mM}$ ammonium formate.

\section{Part III.d. References}

1. Aszalos AA: Modern analysis of antibiotics. New York, Dekker, 1986.

2. Watson DG: Pharmaceutical analysis : a textbook for pharmacy students and pharmaceutical chemists (ed 3rd). Edinburgh, Elsevier Churchill Livingstone, 2012.

3. Flanagan RJ: Fundamentals of analytical toxicology. Chichester, England ; Hoboken, NJ, John Wiley \& Sons, 2007.

4. Wold JS: Rapid analysis of cefazolin in serum by high-pressure liquid chromatography. Antimicrob Agents Chemother 11:105-109, 1977. 
5. Papich MG, Davis JL, Floerchinger AM: Pharmacokinetics, protein binding, and tissue distribution of orally administered cefpodoxime proxetil and cephalexin in dogs. Am J Vet Res 71:1484-1491, 2010.

6. Mouton JW, Theuretzbacher U, Craig WA, et al: Tissue concentrations: do we ever learn? J Antimicrob Chemother 61:235-237, 2008.

7. Waterman NG, Raff MJ, Scharfenberger L, et al: Protein binding and concentrations of cephaloridine and cefazolin in serum and interstitial fluid of dogs. J Infect Dis $133: 642-647,1976$.

8. Fagerquist CK, Lightfield AR: Confirmatory analysis of beta-lactam antibiotics in kidney tissue by liquid chromatography/electrospray ionization selective reaction monitoring ion trap tandem mass spectrometry. Rapid Commun Mass Spectrom $17: 660-671,2003$.

9. Fagerquist CK, Lightfield AR, Lehotay SJ: Confirmatory and quantitative analysis of beta-lactam antibiotics in bovine kidney tissue by dispersive solid-phase extraction and liquid chromatography-tandem mass spectrometry. Anal Chem $77: 1473-1482,2005$.

10. CS Ho, CWK Lam*, MHM Chan, RCK Cheung, LK Law, LCW Lit, KF Ng, MWM Suen, and HL Tai: Electrospray Ionisation Mass Spectrometry: Principles and Clinical Applications. Clin Biochem Rev: 24:3-12, 2003

11. Petrus Hemström and Knut Irgum. "Review: Hydrophilic Interaction Chromatography". J. Sep. Sci. 29 (12): 1784-1821, 2006 


\section{Cefazolin}

\section{Part IV.a. Classification}

Beta lactam antibiotics are composed of a four-member beta-lactam ring which serves as the active site with a second member ring defining the antibiotic as a cephalosporin or penicillin. Cephalosporins have an additional carbon on the second ring, and like most beta-lactam antibiotics, are weak acids. ${ }^{1}$ True cephalosporins are semi-synthetic agents that contain the common 7-aminocephalosporanic acid nucleus which was derived from Cephalosporium acremonium, a fungus. ${ }^{2}$ This nucleus consists of a six membered dihydrothiazine ring fused with the 4 member beta lactam ring. ${ }^{2}$ Cephalosporins are more stable than penicillins and therefore are less susceptible to resistance. ${ }^{1,2}$ Cefazolin is a beta-lactam antibiotic that inhibits cell wall synthesis. ${ }^{1}$

There are many proposed classifications for cephalosporins with the "generation" scheme being the most popularly accepted. ${ }^{1,3}$ This generation scheme initially was developed to group cephalosporins with similar in vitro antimicrobial spectrum, but this scheme does not take into account, the microbiological structure or the bioavailability. ${ }^{2,3}$ Cefazolin is classified as a first generation cephalosporin that is widely used for antimicrobial prophylaxis in human and veterinary medicine because of its minimal toxicity, low cost, and antimicrobial coverage. ${ }^{4,5}$ Although classified as a first generation, Cefazolin has greater antimicrobial activity against gram negative pathogens such as E.coli and Klebsiella pneumoniea which could be due to its substitution of a tetrazole ring at the 7-carbon atom of the nucleus. ${ }^{2,6}$ Reclassifying cephalosporins into groups based on their route of administration and spectrum has been proposed and remains an area of debate. ${ }^{1,3}$ 
Part IV.b. Mechanism of Action

Broadly, beta- lactam antibiotics interfere with bacterial cell wall synthesis which is usually divided into three separate stages. ${ }^{1,2}$ More specifically, a bacterial cell wall consists of several layers of peptidoglycan matrix in which each peptidoglycan strand is composed of five repeating disaccharide units of $\mathrm{N}$-acetylglucosamine and $\mathrm{N}$ acetylmuramate with attached pentapeptides. ${ }^{1}$ These specific pentapeptides are imperative for the final stage of bacterial cell wall synthesis, cross-linking of the peptidoglycan strands. ${ }^{1,2}$ Cross-linking is catalyzed by transpeptidase enzymes (penicillin binding proteins [PBPs]) located in the cell wall. The beta-lactam ring is functionally similar to the terminus of the pentapeptide and acts as a substrate and subsequently inhibits the transpeptidase enzyme. This inhibition leads to increased peptidoglycan precursors, decreased cell wall rigidity, and cell wall degradation. ${ }^{1}$ The number of PBPs varies within the type and species of the bacteria. For example, while a gram positive Staphylococcus sp may have at least four different PBPs, gram negative organisms may have seven. ${ }^{1,2}$ Beta-lactams are most effective against actively growing bacterial populations. ${ }^{2}$ Because organisms are constantly rebuilding, the efficacy of these drugs is dependent on constantly being present during bacterial growth, and therefore are characterized at time dependent antibiotics. ${ }^{1}$

\section{Part IV.c. Pharmacokinetics}

Beta-lactam antibiotics are generally distributed to extracellular fluid, but adequate concentrations of unbound drug can usually be achieved in the interstitial fluid 
which can be predicted by concentration of free (unbound/active) drug in plasma. ${ }^{1}$ Furthermore, cephalosporins are widely distributed in the extracellular fluid throughout most of the body, i.e. kidneys, lungs, bone, and soft tissues. Penetration of cephalosporins into the blood brain barrier or the prostatic tissue is poor. ${ }^{1}$ Penetration of beta-lactam antimicrobials into abscesses and bodily fluids such as peritoneal, pleural and joint fluids, may increase with acute inflammation because of changes in vascular permeability. However those drugs characterized by high binding to plasma protein will likewise be bound to inflammatory proteins and as inflammation decreases the distribution of the bound antimicrobial will change. If inflammation progresses, efficacy of beta-lactams is likely to decrease as a result of poor penetrability of lipid tissue. ${ }^{1}$ Finally these antibiotics in general are eliminated by active tubular secretion in the renal tubules. $^{1}$

Furthermore Cefazolin is widely used in veterinary surgery for its spectrum of activity, rapid peak in tissue concentration, and minimal side effects. ${ }^{6,7}$ In dogs, cefazolin is reported to have variable protein binding (20\%-70\%) in serum, and about $20-35 \%$ protein binding in interstitial fluid with rapid penetration into this space..$^{8,9}$ Additionally, Matushek et al. concluded that cefazolin applied topically to a wound will have rapid and similar serum antibiotic concentration as compared to same antibiotic administered intravenously. ${ }^{10}$ Canine bone models revealed that cefazolin readily penetrates normal and infected bones used in an osteomyelitis model. ${ }^{8}$ In that study, there was an increased maximum extraction of cefazolin in the infected bone which was postulated to be due to an increased permeability or vascularization secondary to inflammation. ${ }^{8}$ In regards to permeability in bone, serum cefazolin concentrations were 
not predictive of the cefazolin concentration in bone, whereas, specifically in surgical wounds, cefazolin paralleled the levels in serum and equilibrated rapidly from serum to surgery site. ${ }^{8,11}$ This relationship was attributed to the unique extravascular space created in a surgical site that had an increased capillary permeability. ${ }^{5,11}$ Based on the ability of cefazolin to stay above the $\mathrm{MIC}_{90}$ for Staphylococcus aureus and Escherichia coli in surgical wounds, it was recommended that an intravenous dose of about $20 \mathrm{mg} / \mathrm{kg}$ for canine patients was used in the perioperative period. ${ }^{5}$ Another study by Richardson et al, found that dogs undergoing total hip arthroplasty had sufficient cefazolin concentrations in the cancellous bone, joint fluid, and joint capsule when evaluated. ${ }^{12}$ Additionally the serum and tissue concentration of cefazolin remained above 15 times the $\mathrm{MIC}{ }_{90}$ after administering $22 \mathrm{mg} / \mathrm{kg}$ of cefazolin every hour. ${ }^{12}$ These results were confirmed with another similar canine total hip arthroplasty study out of the same laboratory. ${ }^{13}$

Other than local drug reactions at the administration sites and occasional hypersensitivity reactions, cephalosporins (i.e. cefazolin) have minimal adverse effects. ${ }^{2}$ It was speculated that cephalosporins that contain the N-methylthiotetrazol (NMTT) side chain may interfere with normal hepatic synthesis of clotting factors by altering hepatic vitamin K synthesis. ${ }^{14}$ Cefazolin is a non-NMTT containing cephalosporin that had no effect on platelet aggregation, bleeding times, platelet count or size, and PT or PTT. ${ }^{14}$ Additionally, clinical assessment of anesthetized dogs suggested a transient episode of hypotension was witnessed following IV administration of certain beta lactam antimicrobials. This theory was disputed in a study where healthy anesthetized dogs were administered an IV bolus of cefazolin and there was no change in HR, blood pressure, oxygen saturation or end tidal respiratory values. ${ }^{7}$ In general, cephalosporins 
are frequently used antibiotics in the perioperative period to decrease the risk of infection. They are potent antimicrobials, relatively safe and obtain satisfactory serum and tissue concentrations in dogs. Because of the spectrum of activity of cefazolin, and common use in the perioperative period, we chose to analyze this antimicrobial in the wound study presented here.

\section{Part IV.d. References}

1. Boothe DM: Small animal clinical pharmacology \& therapeutics (ed 2nd). St. Louis, Mo., Elsevier Saunders, 2012.

2. Caprile KA: The cephalosporin antimicrobial agents: a comprehensive review. J Vet Pharmacol Ther 11:1-32, 1988.

3. Williams JD, Naber KG, Bryskier A, et al: Classification of oral cephalosporins. A matter for debate. Int J Antimicrob Agents 17:443-450, 2001.

4. Birkhead HA, Briggs GB, Saunders LZ: Toxicology of cefazolin in animals. J Infect Dis 128:Suppl:S379-378, 1973.

5. Rosin E, Uphoff TS, Schultz-Darken NJ, et al: Cefazolin antibacterial activity and concentrations in serum and the surgical wound in dogs. Am J Vet Res 54:1317$1321,1993$.

6. Petersen SW, Rosin E: Cephalothin and cefazolin in vitro antibacterial activity and pharmacokinetics in dogs. Vet Surg 24:347-351, 1995. 
7. Morgan MR, Gaynor JS, Monnet E: The effects of sodium ampicillin, sodium cefazolin, and sodium cefoxitin on blood pressures and heart rates in healthy, anesthetized dogs. J Am Anim Hosp Assoc 36:111-114, 2000.

8. Daly RC, Fitzgerald RH, Jr., Washington JA, 2nd: Penetration of cefazolin into normal and osteomyelitic canine cortical bone. Antimicrob Agents Chemother 22:461-469, 1982.

9. Waterman NG, Raff MJ, Scharfenberger L, et al: Protein binding and concentrations of cephaloridine and cefazolin in serum and interstitial fluid of dogs. J Infect Dis 133:642-647, 1976.

10. Matushek KJ, Rosin E: Pharmacokinetics of cefazolin applied topically to the surgical wound. Arch Surg 126:890-893, 1991.

11. Rosin E, Ebert S, Uphoff TS, et al: Penetration of antibiotics into the surgical wound in a canine model. Antimicrob Agents Chemother 33:700-704, 1989.

12. Richardson DC, Aucoin DP, DeYoung DJ, et al: Pharmacokinetic disposition of cefazolin in serum and tissue during canine total hip replacement. Vet Surg 21:14, 1992.

13. Marcellin-Little DJ, Papich MG, Richardson DC, et al: Pharmacokinetic model for cefazolin distribution during total hip arthroplasty in dogs. Am J Vet Res 57:720$723,1996$.

14. Wilkens B, Sullivan P, McDonald TP, et al: Effects of cephalothin, cefazolin, and cefmetazole on the hemostatic mechanism in normal dogs: implications for the surgical patient. Vet Surg 24:25-31, 1995. 


\section{Cefazolin Concentration in Surgically Created Wounds Treated with Negative Pressure Wound Therapy Compared to Surgically Created Wounds Treated with Nonadherent Wound Dressings.}

Julia V. Coutin ${ }^{1}$, DVM; Otto I. Lanz ${ }^{1}$, DVM, DACVS, Geraldine C. Magnin-Bissel ${ }^{2}$, MS, PhD, DABT, Marion F. Ehrich ${ }^{3}$, MS, RPh, PhD, DABT, Emily I. Miller ${ }^{1}$, DVM, DACVS, Stephen R. Werre ${ }^{3}$, PhD, Thomas O. Riegel ${ }^{1}$

From the Departments of Small Animal Clinical Sciences ${ }^{1}$, Research and Graduate Studies $^{2}$ and Biomedical Sciences and Pathobiology ${ }^{3}$, Virginia-Maryland Regional College of Veterinary Medicine, Blacksburg, VA 24061

Address correspondence to Dr. Coutin, Department of Small Animal Clinical Sciences, Virginia-Maryland Regional College of Veterinary Medicine, Phase II Duckpond Dr., Blacksburg, Va 24061, jcoutin@ vt.edu

Funded by the Virginia-Maryland Regional College of Veterinary Medicine Veterinary Memorial Fund.

April 2014 ACCEPTED in Veterinary Surgery 


\section{ABSTRACT}

Objective: To compare cefazolin concentrations in biopsied tissue samples collected from surgically created wounds treated with negative pressure wound therapy to those collected from surgically created wounds treated with nonadherent dressings

Design: Prospective, controlled, experimental study

Animals: 12 female spayed beagles

Methods: Full thickness cutaneous wounds were created on each antebrachium $(n=24)$. Following surgery, cefazolin $(22 \mathrm{mg} / \mathrm{kg})$ was administered intravenously to each of the dogs and continued every 8 hours during the study. The right wound was randomly assigned to group I or group II while the wound on the contralateral antebrachium was assigned to the other group. Group I wounds were treated with negative pressure wound therapy (NPWT) and group II wounds were treated with nonadherent dressings for 3 days. Dressings were changed and tissue biopsies obtained from wound beds at 24-hour intervals for both groups. Cefazolin wound tissue and plasma concentrations were measured by liquid chromatography mass spectrometry (LC-MS/MS). Blood samples for measuring plasma cefazolin concentrations were collected prior to biopsy sampling. At the time of surgery and at each bandage change, wound beds were swabbed and submitted for aerobic and anaerobic culture.

Results: After initiating cefazolin treatment, wound tissue antibiotic concentrations between treatment groups were not significantly different at any sampling time. Similarly, after initiating cefazolin treatment, plasma cefazolin concentrations were not significantly different at any sampling time for individual dogs. 
Conclusions: Using a canine experimental model, NPWT treatment of surgically created wounds does not statistically impact cefazolin tissue concentrations when compared to conventional nonadherent bandage therapy 


\section{INTRODUCTION}

Open wound management is commonly utilized in veterinary medicine with a majority of treatments and dressings performed as dictated by veterinarian comfort and experience. Wound healing is a complex process and still a topic under investigation in both human and veterinary medicine. Based on this research, a plethora of therapies have been suggested for use in the management of open wounds, all aimed at optimizing the healing process. Currently used therapies for the treatment of open wounds include lavage solutions, topical antimicrobial agents, occlusive and semi-occlusive dressings, nonadherent dressings, oxygen therapy, systemic antimicrobials, and, more recently, negative pressure wound therapy (NPWT). ${ }^{1-3}$

Over 10 years ago, Fleischmann and Morykwas introduced the concept of applying negative pressure to wounds in order to promote rapid wound healing. ${ }^{4,5}$ NPWT was initially developed for the treatment of non-healing wounds and for wound treatment either in preparation for surgery or as an alternative treatment to surgery in debilitated patients. ${ }^{6,7}$ Recent studies were conducted in order to add insight to the understanding of the mechanism of action of NPWT. NPWT is thought to promote wound healing by the early generation of granulation tissue, increasing vascular perfusion, reducing wound edema, altering chronic wound fluid composition, and cellular microdeformation. ${ }^{5,7-13}$ Although there are numerous studies investigating the mechanisms of action of NPWT, rapid wound healing seen with this modality is not completely understood. Despite recent advances, there is minimal literature using NPWT in the veterinary clinical setting. $^{14-21}$ 
Systemic antibiotic administration is often used as an adjunctive therapy to local wound treatment and is ideally based on culture and susceptibility, local antimicrobial concentration and penetration, expected bacterial flora and bacterial resistance patterns. ${ }^{1}$ Cefazolin is a first generation cephalosporin which is commonly used for surgery because of its rapid distribution between the soft tissues, bone, and surgical sites. ${ }^{22-25}$ Additionally, cefazolin is a commonly selected antibiotic because of its spectrum of activity against a variety of bacterial pathogens commonly encountered..$^{22,23,25}$ Trauma associated with surgery creates a unique extravascular environment with increased capillary permeability in dogs. ${ }^{22-24}$ Due to this unique environment, the antibiotic equilibrates rapidly between the serum and surgical wound. ${ }^{22,23}$ A recent study evaluated antibiotic concentration of wounds treated with NPWT and compared the peak antibiotic concentration of the wound fluid to the increase in serum antibiotic concentration. ${ }^{26}$ This study concluded that adequate antibiotic concentrations were achieved in the NPWT treated wounds. ${ }^{26}$

To the authors' knowledge, there are no studies comparing antibiotic tissue concentrations sampled from wounds treated with NPWT to those from wounds treated with nonadherent dressings following parenteral antibiotic treatment of dogs. Therefore the aims of this study are to compare antibiotic concentration in surgically created wounds treated with NPWT to antibiotic concentration in surgically created wounds treated with nonadherent wound dressings, and secondly, to record bacterial growth from aerobic/anaerobic wound cultures. The work presented here tested the hypothesis that there would be a statistical difference in antibiotic tissue concentrations between 
surgically created wounds treated with NPWT compared to surgically created wounds treated with nonadherent dressings.

\section{MATERIALS AND METHODS}

Twelve adult (16-20 month old) female spayed Beagle dogs weighing between 7$12 \mathrm{~kg}$ were studied. Dogs were considered healthy based on physical examination, complete blood count, serum biochemical profile, and urinalysis. All procedures were approved by the Institutional Animal Care and Use Committee (IACUC) at the Virginia Polytechnic Institute and State University. Dogs with any concurrent infections (e.g. urinary tract, skin or other locations) or receiving antimicrobials 30 days before surgery were not included in the study. Subjects were excluded from the study if they became systemically ill or developed wound complications necessitating deviation from the wound treatment protocol. Dogs were also excluded from the study if there was a loss of negative pressure in the NPWT treated wounds for greater than 4 hours.

\section{Surgical Procedure and Sample Collection}

On day 1 of the study, each dog was premedicated with hydromorphone $(0.1$ $\mathrm{mg} / \mathrm{kg}$, intramuscularly [IM]) and acepromazine maleate $(0.05 \mathrm{mg} / \mathrm{kg}, \mathrm{IM})$ and anesthetized with propofol (4-6 mg/kg, intravenously [IV] to effect). Prior to induction of anesthesia on the first day of the study, blood samples were taken from the dogs by jugular venipuncture. Plasma was used for antibiotic concentration analysis. After endotracheal intubation, anesthesia was maintained with isoflurane (1-2\% delivered in 
oxygen). The patient was placed in dorsal recumbency and both forelimbs were clipped from 2 inches proximal to the scapulohumeral joint laterally and circumferentially to ventral midline and continuing distally to the carpometacarpal joint. Each patient was prepared for aseptic surgery in a routine fashion, and surgical asepsis was maintained throughout the procedure. A $2 \mathrm{~cm}$ x $2 \mathrm{~cm}$ square sterile template was used to create a standard wound that was located $2.5 \mathrm{~cm}$ distal from the proximal aspect of the olecranon on the lateral aspect of the antebrachium (Fig 1). After the wound boundaries were outlined, a \#15 scalpel blade was used to create the full thickness skin defect. A $4 \mathrm{~mm}$ punch biopsy was then used to obtain a tissue sample from the wound bed. Tissue biopsies were used for cefazolin concentration measurements. Hemostasis was achieved using sterile gauze and digital pressure. A sterile culture swab was then passed over the wound bed. The procedure was repeated on the opposite limb. After the biopsy and culture samples were obtained, cefazolin $(22 \mathrm{mg} / \mathrm{kg}, \mathrm{IV})$ was administered through a peripheral intravenous catheter. A peripheral long intravenous lateral saphenous catheter was utilized through the study period for cefazolin administration. Cefazolin was then administered intravenously every 8 hours for the duration of the study. Jugular venipuncture was subsequently performed on study days 2,3 , and 4 prior to obtaining tissue biopsies. The first wound tissue biopsy was taken at the time of the initial surgery and subsequently at 24 hour intervals thereafter at times of bandage changes for three additional days. The time between plasma sample collection and tissue sample collection ranged around 20-50 minutes. All samples (plasma and tissue biopsies) were frozen at $80^{\circ} \mathrm{C}$ until processed for analysis. The samples were analyzed within 3 months after sample collection. 
Prior to the surgical procedure, the right antebrachium was randomly assigned to one of two groups (group I or group II) based on a coin toss, and the contralateral antebrachium was then placed in the opposite group (Table 1). This was done so no dog would have both wounds treated in the same way. Group dressings were maintained on the assigned antebrachium throughout the study period. Group I wounds were treated with NPWT. The NPWT dressing consisted of an open cell polyurethane ether foam (V.A.C. ${ }^{\circledR}$, GranuFoam $^{\circledR}$, Kinetic Concepts Inc., San Antonio, TX) placed as a primary bandage layer, impermeable adhesive drape covering the foam, and a flat perforated disc (V.A.C. ${ }^{\circledR}$, T.R.A.C. ${ }^{\circledR}$ Pad, Kinetic Concepts Inc., San Antonio, TX) which was attached to evacuation tubing connected to a vacuum pump (Fig 2). The vacuum was set to provide continuous negative pressure at $-125 \mathrm{mmHg}$ for the duration of the study. The NPWT dressing was covered with cast padding as the secondary bandage layer, soft bandage roll (Kling Gauze bandage, Johnson and Johnson Products Inc, New Brunswick, $\mathrm{NJ})$ as the tertiary bandage layer, and a self-adhesive bandage (3M $\mathrm{M}^{\mathrm{TM}}$ Vetrap ${ }^{\mathrm{TM}}$, St. Paul, $\mathrm{MN}$ ) as the protective layer. The vacuum unit (V.A.C. ${ }^{\circledR}$ Simplicity ${ }^{\mathrm{TM}}$, Kinetic Concepts Inc., San Antonio, TX) was then attached to the patient harness to allow for mobility (Fig 3). The $\mathrm{VAC}^{\circledR}$ Simplicity ${ }^{\mathrm{TM}}$ units were checked at least every 4 hours to ensure there was not a loss of negative pressure, blockage of the evacuation system, or loss of battery.

Group II wounds were treated with a semiocclusive, nonadherent bandage, which consisted of a petroleum-impregnated primary layer dressing (Adaptic ${ }^{\circledR}$, Johnson \& Johnson, New Brunswick, NJ). Secondary and tertiary bandage layers were applied as previously described for the NPWT treated group. Both groups were bandaged from the digits to just proximal to the elbows (Fig 3). Both bandages were changed at 24-hour 
intervals under sedation on study days 2,3 , and 4 . For each bandage change, animals were sedated with dexmedetomidine (5 mcg/kg, IV) and butorphanol $(0.2 \mathrm{mg} / \mathrm{kg}$, IV). Using a $4 \mathrm{~mm}$ biopsy punch, wound tissue samples were obtained at the time of bandage changes (approximately one hour after morning cefazolin administration) and submitted for cefazolin concentration analysis. A sterile culture swab was then passed over the wound bed prior to replacing the wound dressings. Atipamezole $(0.05 \mathrm{mg} / \mathrm{kg} \mathrm{IM})$ was administered for reversal of sedation. Every 4 hours the dogs were evaluated for loss of negative pressure or bandage complications such as strike-through, swollen digits, or mutilation.

Cefazolin analysis by Liquid Chromatography Mass Spectrometry (LC-MS/MS)

Cefazolin concentration was determined by LC-MS/MS using a previously described method. ${ }^{27-30}$ Cefazolin sodium salt was purchased from Sigma-Aldrich (St Louis, MO) and ceftezole sodium salt (internal standard) from Waterstone Technology (Carmel, IN). Solutions of cefazolin and ceftezole at various concentrations were prepared in water. The solid phase extraction (SPE) cartridges Oasis HLB 1cc, 30mg were purchased from Waters Corporation (Milford, MA). All the solvents used were LCMS/MS grade.

Tissue samples were weighed with an analytical balance Ohaus (Parsippany, NJ). Tissue homogenization was performed with a homogenizer Kinematica CH-6010 from Brinkman Instruments (Westbury, NJ). A centrifuge Centra CL3R from Thermo Electro Co (Waltham, MA) was used to centrifuge the tissue sample after homogenization. A microcentrifuge Eppendorf 5415R (Hamburg, Germany) was used to centrifuge the 
plasma samples and the prepared samples prior to analysis. The SPE was performed under vacuum with a 12-port vacuum manifold connected to a vacuum/pressure station, Air Cadet from Fisher Scientific (Pittsburg, PA). Extracted samples were evaporated using a Pierce Reacti-Therm III ${ }^{\mathrm{TM}}$ heating module from Thermo Fisher Scientific (Rockford, IL) including 27 ports connected to nitrogen. Samples were analyzed using a liquid chromatography system 1100 Series Agilent Technologies (Santa Clara, CA) interfaced with a mass spectrometer QTrap 3200 from AB SCiex (Framingham, MA). The Analyst software was used to run the instrument and proceed to the data analysis. Chromatographic separation was performed with a HPLC column XBridge HILIC 100 mm x $2.1 \mathrm{~mm}, 3.5 \mu$ from Waters Corporation (Milford, MA).

Calibration curves were generated. Solutions of cefazolin were prepared in water at the following concentrations: $0.1,0.5,1,5.0,10,50$ and $100 \mathrm{ppm}$ for the calibration curve in plasma and $0.1,0.5,1,2.5,5.0,7.5$ and $10 \mathrm{ppm}$ for the calibration curve in tissue homogenates. Negative controls without standard or internal standard were used to check for possible interferences.

The calibration curves were prepared by adding $50 \mu \mathrm{l}$ of cefazolin standard, $20 \mu \mathrm{l}$ of ceftezole $10 \mathrm{ppm}$ in water and $700 \mu \mathrm{l}$ of $4 \%$ aqueous phosphoric acid to $50 \mu \mathrm{l}$ of blank plasma or blank muscle tissue homogenate (not containing cefazolin). The mixtures were centrifuged at $16,000 \mathrm{~g}$ for $5 \min \left(4^{\circ} \mathrm{C}\right)$ and the supernatants were cleaned by SPE.

$20 \mu \mathrm{l}$ of ceftezole $10 \mathrm{ppm}$ and $700 \mu \mathrm{l}$ of aqueous phosphoric acid $4 \%$ were added to $50 \mu \mathrm{l}$ of plasma sample to acidify the mixture. After mixing for 20 seconds, the mixture was centrifuged at $16,000 \mathrm{~g}$ for $5 \mathrm{~min}$ at $4^{\circ} \mathrm{C}$ and the supernatant was cleaned by SPE. 
Tissue samples were thawed on ice before homogenization. Each tissue sample (between $20-60 \mathrm{mg}$ ) was transferred to a glass tube and homogenized in $1.5 \mathrm{ml}$ of water. The tube was centrifuged at $3,000 \mathrm{~g}$ for $5 \mathrm{~min}$ at $4^{\circ} \mathrm{C} .10 \mu \mathrm{l}$ of ceftezole $10 \mathrm{ppm}$ and 700 $\mu \mathrm{l}$ of aqueous phosphoric acid $4 \%$ were added to $50 \mu \mathrm{l}$ of the tissue supernatant. The mixture was centrifuged at $16,000 \mathrm{~g}$ for $5 \mathrm{~min}\left(4^{\circ} \mathrm{C}\right)$ and the supernatant was cleaned by SPE.

For the SPE, the cartridges were conditioned with $1 \mathrm{ml}$ of methanol followed by 1 $\mathrm{ml}$ of water. The sample extract was loaded slowly on the cartridge. The cartridge was washed with $1 \mathrm{ml}$ of aqueous ammonium formate $10 \mathrm{mM}$ followed by $1 \mathrm{ml}$ of watermethanol (80:20). The cartridge was allowed to dry for 1 minute under vacuum before cefazolin was eluted with $2 \mathrm{ml}$ of methanol. The methanol was evaporated under a stream of nitrogen at $20^{\circ} \mathrm{C}$ and the residue was reconstituted in $200 \mu \mathrm{l}$ of the mobile phase. The extract was centrifuged at $16,000 \mathrm{~g}$ for $5 \mathrm{~min}$ before analysis.

The mobile phase consisted in a mixture of acetonitrile-water (95:5) with $0.1 \%$ formic acid and $2 \mathrm{mM}$ ammonium formate in an isocratic condition and the column was washed periodically with a mixture of acetonitrile water (50:50) and $0.1 \%$ formic acid. The temperature of the column was not controlled. The flow rate was $400 \mu 1 / \mathrm{min}$. The injection volume was $10 \mu \mathrm{l}$. In these conditions, cefazolin and ceftezole were separated chromatographically. The ion source parameters were the following: curtain gas (CUR): 10.00 psig; ion Spray Voltage (IS): $5500 \mathrm{~V}$; temperature: $600{ }^{\circ} \mathrm{C}$; ion source gas 1 (GS1): $50 \mathrm{psig}$, ion source gas 2 (GS2): $50 \mathrm{psig}$; collision gas (CAD): medium, interface heater (ihe): on. The MS/MS analysis was performed by Multiple Reaction Monitoring (MRM) in positive mode. Cefazolin was quantified by the transitions $\mathrm{m} / \mathrm{z}$ (mass over charge 
ratio) $454.9>323.0$ and 454.9>155.9 and ceftezole by the transition $m / z$ 440.9>323.0. The resolution for Q1 and Q3 was set as low. The dwell time was $150 \mathrm{msec}$. The calibration curves were prepared by plotting the ratio of abundances of cefazolin and ceftezole versus the concentration of cefazolin. No interference was noted in the negative plasma control or in the negative tissue control prior to treatment with cefazolin. The calibration curves in plasma and tissue were linear between 0.1 and $100 \mathrm{ppm}$ with a coefficient of correlation $>0.99$. The recoveries were measured by comparing the abundances of the internal standard in the extracted sample to the abundance of the internal standard in a negative control spiked after SPE. The recoveries in plasma and tissue were between $80 \%$ and $90 \%$. For the plasma extraction, the intra-day variability was $6 \%$ and the inter-day variability was $8 \%$. The limit of detection (LOD) and limit of quantitation (LOQ) were defined as the concentrations which yield a measure peak with a signal over noise ratio $(\mathrm{S} / \mathrm{N})$ of 3 and 10 respectively. The LOD of cefazolin in plasma and tissue were $0.03 \mathrm{ng}$ and $0.25 \mathrm{ng}$ respectively. The LOQ of cefazolin in plasma and tissue were $0.10 \mathrm{ng}$ and $0.75 \mathrm{ng}$ respectively.

\section{Aerobic and Anaerobic Bacterial Cultures}

After surgical creation of the wounds, a sterile bacterial culture swab was passed once across the wound bed of each wound from a proximal to distal direction. Care was taken to remain within the wound defect and not contact the surrounding tissues. The wounds were then bandaged according to the specific group protocol. Additional culture samples were obtained at bandage changes on days 2, 3, and 4. All samples submitted for aerobic culture were plated on MacConkey and blood agar plates. The blood agar 
plates were incubated in a $7.5 \%$ carbon dioxide incubator set at a temperature of $35^{\circ} \mathrm{C}$. MacConkey plates were placed in a $35^{\circ} \mathrm{C}$ room air incubator. Colony growth was evaluated after approximately 24,48 , and 72 hours of incubation. After 72 hours if there was no growth, the sample was finalized as, "no growth". If there was growth, it was examined for purity in order to identify the organism. The quantity of an isolate was estimated using a $1+$ to $4+$ system. Small growth was represented by $1+$, usually restricted to the first quadrant whereas diffuse growth in each quadrant was represented by $4+$. If the culture contained a mixed population, it would be sub-cultured until pure cultures were obtained. Samples submitted for anaerobic culture were plated on Brucella agar with Hemin and Vitamin K specialized as an anaerobic growth plate. Once the sample was plated, it was placed in a plastic pouch with a Pouch-anaero sachet (Remel, Thermo Fisher Scientific, Lenexa, KS) used to generate a gas environment for cultivation of anaerobic bacteria. The sample was placed in an incubator where growth was evaluated after approximately 48 hours. Quantity was reported as described above. Identification of organisms was performed according to the standard operating procedures for this institution's laboratory. ${ }^{31,32}$

\section{Statistical Analysis}

The primary outcome was tissue cefazolin concentration. A secondary outcome included plasma cefazolin concentrations within each dog at study days 2, 3, and 4. Another secondary outcome was the presence or absence of bacterial growth on culture of each wound. Normal probability plots showed that tissue and plasma cefazolin concentrations were normally distributed. Subsequently, cefazolin concentrations were 
summarized as mean $\pm \mathrm{SD}$. To test the null hypothesis that cefazolin concentration in wounds treated with NPWT is equal to cefazolin concentration in wounds treated with nonadherent dressings, data was analyzed using mixed-model analysis of variance. The linear model specified treatment (NPWT vs. nonadherent dressings), day, and treatment*day as fixed effects with Kenward-Roger as the denominator degrees of freedom was set. Dog identification was specified as the random effect. To specifically compare treatments on each day, the treatment*day interaction was further evaluated with the slicediff option of the glimmix procedure. The effect of day on plasma cefazolin concentration was also evaluated using mixed-model analysis of variance. The linear specified day as a fixed effect, Kenward-Roger as the denominator degrees of freedom and dog identification as the random effect was set. Where applicable, p-values were adjusted for multiple comparisons using Tukey's procedure. On each day, the number of cultures with bacterial growth was compared between the two groups using McNemar's Chi-square test. A P value $<0.05$ was considered to be statistically significant. All statistical analyses were performed using SAS version 9.3(Cary, NC, USA).

\section{RESULTS}

None of the 12 adult, female spayed purpose bred Beagles were excluded during the study. The dogs had a mean $( \pm \mathrm{SD})$ age of $17.5 \pm 1.5$ months with a mean body weight of $9.4 \pm 0.87 \mathrm{~kg}$. All dogs had complete blood count, serum biochemical profile, and urinalysis parameters within normal range. All dogs tolerated the backpack and were able to maneuver freely within their kennels. Two dogs (Dog 5 and 7) lost negative pressure within the 4 hour evaluation interval on the last day of the collection period. 
The canister tubing was cracked in both dogs and was therefore changed. No further loss of negative pressure was encountered. Following completion of the study, all wounds healed by second intention without complication. Wound healing was complete around 2 weeks after the project termination.

\section{Antibiotic concentration}

Plasma cefazolin concentration was non-detectable on the initial day prior to surgery in all dogs. On each subsequent day, mean $( \pm \mathrm{SD})$ plasma cefazolin concentrations were $40.12 \pm 8.84 \mathrm{ppm}, 39.58 \pm 10.78 \mathrm{ppm}$, and $38.92 \pm 12.94 \mathrm{ppm}$ on study days 2, 3, and 4, respectively. After initiation of antibiotic treatment, plasma concentrations at the time of sample collection for individual dogs were not significantly different.

Cefazolin tissue concentrations in wounds treated with NPWT were nondetectable in the initial biopsies prior to cefazolin initiation. Average $( \pm$ SD) cefazolin tissue concentrations for NPWT treated wounds were $15.47 \pm 6.33 \mathrm{ppm}, 19.98 \pm 8.91$ ppm, and $21.04 \pm 8.42$ ppm on study days 2,3 , and 4, respectively. Similarly, cefazolin tissue concentrations in wounds treated with nonadherent wound dressings were nondetectable in the initial biopsies prior to cefazolin initiation. Average $( \pm S D)$ cefazolin concentrations for wounds treated with nonadherent dressings were $13.23 \pm 4.32 \mathrm{ppm}$, $15.89 \pm 5.12 \mathrm{ppm}$, and $19.35 \pm 5.50 \mathrm{ppm}$ on study days 2,3 , and 4 respectively. After initiation of antibiotic treatment, cefazolin tissue concentrations between treatment groups were not statistically significant at any time during the study (Figure 4).

\section{Microbiology}


Ninety six cultures swabs were placed onto aerobic and anaerobic culture media. Two samples were positive for aerobic culture with no positive anaerobic cultures. One of the positives was from a wound treated with a nonadherent dressing on study day 2. The organisms identified were a Corynebacterium spp. and Staphylococcus epidermidis, which were not cultured on study days 3 and 4 of the same wound. The second positive sample was identified as Kocuria rosea. This organism was isolated form the swab obtained after wound creation and prior to bandage placement in Dog 1 and was considered a contaminant. This organism was not isolated from subsequent samples. There was no gross delay in wound healing or clinical signs associated with wound infection in any of the wounds throughout the study. There was no significant difference in bacteriologic cultures between either of the wound groups. Bacterial culture statistics for nonadherent wound treated group compared to NPWT treated group were as follows: study day $1(1 / 12$ vs. $0 / 12)(\mathrm{P}=0.617)$, study day 2 (1/12 vs. $0 / 12)(\mathrm{P}=0.617)$, study day 3 (0/12 vs. $0 / 12)(\mathrm{P}=1.000)$ and study day $4(0 / 12$ vs. $0 / 12)(\mathrm{P}=1.000)$.

\section{DISCUSSION}

Our results revealed no significant difference in cefazolin tissue concentrations between the treated groups at any time during this project. Intuitively, the rapid development of granulation tissue and possible increased perfusion after NPWT could increase local antibiotic concentration as compared to wounds treated with traditional nonadherent dressings. However, the effect of NPWT on wound perfusion is debatable with conflicting studies reporting on perfusion to the wound and adjacent tissues. ${ }^{33,34}$ Interestingly, there is one investigation noting beta-lactam antibiotic tissue penetration 
may be hindered in the face of increased inflammatory mediators which may have altered local antibiotic concentrations. ${ }^{35}$ To the authors' knowledge, the connection between inflammatory modulation by NPWT and wound antibiotic penetration has not been evaluated to date.

Microvascular blood flow studies found varying effects of NPWT on vascular perfusion depending on the tissue type as well as the distance from the wound. ${ }^{33,34}$ Varying cutaneous Doppler studies reported that there was an increase in vascular perfusion of wounds beneath the NPWT dressing, but recently, another group concluded there was a decrease in blood flow to tissues treated with NPWT as dictated by pertechnetate radioisotope imaging. ${ }^{36-38}$ Whether NPWT increases or decreases the vascular perfusion to the treated area, this study found that antibiotic concentration does not seem to be affected in the acute period. Additionally, the biopsy technique and antibiotic concentration analysis in this study included muscle, subcutaneous tissue and fascia. Vascular perfusion to various tissue types is again variably affected by NPWT. ${ }^{33,34,39}$ Although the presence of granulation tissue could have altered our findings, our study utilized an acute wound model and biopsies were obtained prior to visual formation of granulation tissue even though tissue samples were not submitted for histopathological evaluation. Although cefazolin is reported to equilibrate well between canine plasma and the surgical wound, ${ }^{22,23,40}$ this is the first study which investigated the effect of NPWT on tissue antibiotic concentrations when compared to those from traditional bandage therapy for dog wounds. In that respect, and in agreement with another recent study ${ }^{26}$ NPWT did not hinder antibiotic concentration in tissue samples 
from wounds when compared to a control bandage group, and both treatment groups had comparable cefazolin tissue concentrations at the time of biopsy.

Beta lactam antibiotic penetration can be affected in inflammatory environments, ${ }^{25,35}$ which may play a role in the lack of difference in antibiotic concentration despite increased blood flow and capillary density due to NPWT. ${ }^{10}$ The effects of NPWT on inflammatory cytokines in acute wounds were reported recently in attempts to understand the role of NPWT on accelerated granulation tissue formation. NPWT was acclaimed to ameliorate inflammation due to increases in the antiinflammatory cytokine, interleukin-10 (Il-10), but also was reported to increase the chemoattractant interleukin-8 (Il-8) due to an increase in oxygen partial pressure further leading to neutrophil-mediated expression of vascular endothelial growth factor (VEGF). ${ }^{41,42}$ Repeatedly, VEGF was shown to increase vascular permeability which can impair beta lactam target site penetration. ${ }^{35,43,44}$ Given the lack of difference in tissue antibiotic concentrations between the treated groups in our study, it would be interesting to investigate if acute inflammation in wounds treated with NPWT can be more definitively defined in the dog and if this inflammation could possibly explain the lack of difference in antibiotic concentration of wounds treated with NPWT as compared to nonadherent dressings.

As a secondary outcome of the study, there was no statistical difference in microbiologic results from treatment by either group in this study. This is not entirely unexpected due to the aseptic surgical creation of these wounds, short duration of the study, and daily bandage changes. The effect of NPWT on wound bioburden is one of the more controversial mechanisms of action originally proposed by Fleischmann and 
Morykwas. ${ }^{4,5}$ Initially, when investigating the mechanism of action of NPWT on surgically created wound defects in pigs, $1 \mathrm{ml}$ of saline with $10^{8}$ organisms of either Staphylococcus aureus or Staphylococcus epidermidis was injected into the wounds. ${ }^{5}$

Biopsy samples were taken daily during bandage changes, and the number of organisms per gram of tissue decreased significantly between days 4 and $5 .^{5}$ Following this report, additional studies and case series supported a decrease in bacterial wound burden. ${ }^{6,45,46}$ Contrary to these reports, the potential for NPWT to decrease bacterial wound burden was questioned in recent human and veterinary literature. ${ }^{16,46-48}$ Toxic shock syndrome and increased anaerobic bacterial burden are complications that were reported with NPWT. $^{49,50}$ In a recent canine, controlled, prospective study by Demaria et al., although wounds treated with NPWT showed an increase in bacterial contamination, none of the wounds had evidence of infection or delayed wound healing. ${ }^{16}$ That study also obtained microbial cultures starting on day 7 which was later then the cultures obtained in our study, therefore we postulate that the short duration of the study and daily wound care, in addition to a small population size, and concurrent antibiotic therapy may have precluded further positive bacteriologic cultures. We can only comment on the negative culture results in our study and therefore, cannot make a conclusion as to whether either dressing material prevented or promoted positive wound cultures. The lack of delayed wound healing in the face of positive bacterial cultures seen in previous studies, as well as in our study, highlights the importance of other mechanisms by which NPWT promotes granulation tissue and wound healing.

This study does have inherent limitations that should be appreciated. First is with regard to interpreting the wound tissue antibiotic concentration data. Wound biopsies 
were utilized to detect antibiotic concentration as opposed to devices, such as an ultrafiltration sampling kit or a microdialysis catheter, to measure the antibiotic concentration specifically in the interstitial fluid of the wound. ${ }^{51,52}$ Homogenizing tissue biopsies combined the interstitial fluid, cells and subcellular organelles which may have resulted in dilution and underestimation of the antibiotic concentration of cefazolin which is a compound mainly distributed extracellularly. ${ }^{52,53}$ Although, tissue is made of distinct compartments, surgical wounds create a unique extracellular environment in which systemic antibiotics were reported to equilibrate rapidly. ${ }^{22,23,26}$ The effect of NPWT or nonadherent dressings on local tissue cefazolin concentration was the main outcome of the research presented here. This study does not provide any information about the cefazolin concentration in specific tissue compartments or local drug effect. Additional investigations could be performed to characterize the antibiotic activity and compartment distribution within wounds treated with NPWT. Secondly, more dogs included in the study would have increased the power of the analysis. Finally, correlation between the plasma and tissue concentrations was not able to be made because the samples, although taken within the same anesthetic period, were taken at different times. As other studies have already concluded, cefazolin and cephalosporins rapidly equilibrate between plasma and surgical wounds and, therefore, this determination was not our goal. The primary outcome of this investigation was to compare the wound tissue antibiotic concentration between wounds treated with either NPWT or nonadherent dressings. ${ }^{22,23,26}$

In conclusion, we found no significant difference in cefazolin tissue concentrations in wounds treated with NPWT or nonadherent dressings when measured by tissue biopsy and LC-MS/MS. Cefazolin tissue concentrations were similar between 
groups and therefore systemic cefazolin delivery to wounds treated with NPWT can be expected to be similar to the delivery in wounds treated with traditional nonadherent dressings. The complex mechanisms by which NPWT benefits wound healing is an interesting area that warrants further investigation.

\section{ACKNOWLEDGEMENTS}

The authors would like to thank Dana Callicot, Karen Hall, and Nicole Lindstrom for their assistance during the study period.

\section{Part V.a. References}

1. Krahwinkel DJ, Boothe HW, Jr. Topical and systemic medications for wounds. Vet Clin North Am Small Anim Pract 2006;36:739-757.

2. Fahie MA, Shettko D. Evidence-based wound management: a systematic review of therapeutic agents to enhance granulation and epithelialization. Vet Clin North Am Small Anim Pract 2007;37:559-577.

3. Brumbaugh GW. Use of antimicrobials in wound management. Vet Clin North Am Equine Pract 2005;21:63-75.

4. Fleischmann W, Becker U, Bischoff M, et al. Vacuum sealing: indication, technique, and results. European Journal of Orthopaedic Surgery \& Traumatology $1995 ; 5: 37-40$. 
5. Morykwas MJ, Argenta LC, Shelton-Brown EI, et al. Vacuum-assisted closure: a new method for wound control and treatment: animal studies and basic foundation. Ann Plast Surg 1997;38:553-562.

6. Argenta LC, Morykwas MJ. Vacuum-assisted closure: a new method for wound control and treatment: clinical experience. Ann Plast Surg 1997;38:563-576; discussion 577.

7. Plikaitis CM, Molnar JA. Subatmospheric pressure wound therapy and the vacuum-assisted closure device: basic science and current clinical successes. Expert Rev Med Devices 2006;3:175-184.

8. Hunter JE, Teot L, Horch R, et al. Evidence-based medicine: vacuumassisted closure in wound care management. Int Wound J 2007;4:256-269.

9. Morykwas MJ, Simpson J, Punger K, et al. Vacuum-assisted closure: state of basic research and physiologic foundation. Plastic and reconstructive surgery 2006; 117:121S.

10. Chen SZ, Li J, Li XY, et al. Effects of vacuum-assisted closure on wound microcirculation: an experimental study. Asian J Surg 2005;28:211-217.

11. Saxena V, Hwang CW, Huang S, et al. Vacuum-assisted closure: microdeformations of wounds and cell proliferation. Plast Reconstr Surg 2004;114:10861096; discussion 1097-1088.

12. Scherer SS, Pietramaggiori G, Mathews JC, et al. The mechanism of action of the vacuum-assisted closure device. Plast Reconstr Surg 2008;122:786-797. 
13. McNulty AK, Schmidt M, Feeley T, et al. Effects of negative pressure wound therapy on fibroblast viability, chemotactic signaling, and proliferation in a provisional wound (fibrin) matrix. Wound Repair Regen 2007;15:838-846.

14. Adkesson MJ, Travis EK, Weber MA, et al. Vacuum-assisted closure for treatment of a deep shell abscess and osteomyelitis in a tortoise. J Am Vet Med Assoc 2007;231:1249-1254.

15. Ben-Amotz R, Lanz OI, Miller JM, et al. The use of vacuum-assisted closure therapy for the treatment of distal extremity wounds in 15 dogs. Vet Surg 2007;36:684-690.

16. Demaria M, Stanley BJ, Hauptman JG, et al. Effects of negative pressure wound therapy on healing of open wounds in dogs. Vet Surg 2011;40:658-669.

17. Guille AE, Tseng LW, Orsher RJ. Use of vacuum-assisted closure for management of a large skin wound in a cat. J Am Vet Med Assoc 2007;230:1669-1673.

18. Kirkby K, Wheeler J, Farese J, et al. Surgical views: vacuum-assisted wound closure: clinical applications. Compendium (Yardley, PA) 2010;32:E1.

19. Kirkby KA, CCRT D, Wheeler JL, et al. Vacuum-assisted wound closure: application and mechanism of action. Compend Contin Edu Vet 2009;31:578-576.

20. Lafortune M, Fleming GJ, Wheeler JL, et al. Wound management in a juvenile tiger (Panthera tigris) with vacuum-assisted closure (V.A.C. Therapy). J Zoo Wildl Med 2007;38:341-344.

21. Owen L, Hotston-Moore A, Holt P. Vacuum-assisted wound closure following urine-induced skin and thigh muscle necrosis in a cat. Vet Comp Orthop Traumatol 2009;22:417-421. 
22. Rosin E, Uphoff TS, Schultz-Darken NJ, et al. Cefazolin antibacterial activity and concentrations in serum and the surgical wound in dogs. Am J Vet Res $1993 ; 54: 1317-1321$.

23. Rosin E, Ebert S, Uphoff TS, et al. Penetration of antibiotics into the surgical wound in a canine model. Antimicrob Agents Chemother 1989;33:700-704.

24. Marcellin-Little DJ, Papich MG, Richardson DC, et al. Pharmacokinetic model for cefazolin distribution during total hip arthroplasty in dogs. Am J Vet Res 1996;57:720-723.

25. Boothe DM. Small animal clinical pharmacology \& therapeutics. 2nd ed. St. Louis, Mo.: Elsevier Saunders, 2012.

26. Bischoff M, Beck A, Frei P, et al. Pharmacokinetics of cefuroxime in traumatic wound secretion and antibacterial activity under vacuum therapy. J Chemother 2010;22:92-97.

27. Fagerquist CK, Lightfield AR. Confirmatory analysis of beta-lactam antibiotics in kidney tissue by liquid chromatography/electrospray ionization selective reaction monitoring ion trap tandem mass spectrometry. Rapid Commun Mass Spectrom $2003 ; 17: 660-671$.

28. Fagerquist CK, Lightfield AR, Lehotay SJ. Confirmatory and quantitative analysis of beta-lactam antibiotics in bovine kidney tissue by dispersive solid-phase extraction and liquid chromatography-tandem mass spectrometry. Anal Chem 2005;77:1473-1482.

29. Colin P, De Bock L, T'Jollyn H, et al. Development and validation of a fast and uniform approach to quantify beta-lactam antibiotics in human plasma by solid 
phase extraction-liquid chromatography-electrospray-tandem mass spectrometry. Talanta 2013;103:285-293.

30. Wold JS. Rapid analysis of cefazolin in serum by high-pressure liquid chromatography. Antimicrob Agents Chemother 1977;11:105-109.

31. Versalovic J, Carroll KC, Funke G, et al. Manual of clinical microbiology (ed 10). Washington, DC, ASM Press, 2011.

32. Quinn PJ, Markey BK, Carter ME, et al. Veterinary microbiology and microbial disease. Malden, MA, Blackwell Science, 2002.

33. Wackenfors A, Sjogren J, Gustafsson R, et al. Effects of vacuum-assisted closure therapy on inguinal wound edge microvascular blood flow. Wound Repair Regen 2004;12:600-606.

34. Borgquist $\mathrm{O}$, Ingemansson R, Malmsjo M. Wound edge microvascular blood flow during negative-pressure wound therapy: examining the effects of pressures from -10 to -175 mmHg. Plast Reconstr Surg 2010;125:502-509.

35. Joukhadar C, Frossard M, Mayer BX, et al. Impaired target site penetration of beta-lactams may account for therapeutic failure in patients with septic shock. Crit Care Med 2001;29:385-391.

36. Kairinos N, Voogd AM, Botha PH, et al. Negative-pressure wound therapy II: negative-pressure wound therapy and increased perfusion. Just an illusion? Plast Reconstr Surg 2009;123:601-612.

37. Kairinos N, Solomons M, Hudson DA. Negative-pressure wound therapy I: the paradox of negative-pressure wound therapy. Plast Reconstr Surg 2009;123:589598; discussion 599-600. 
38. Timmers MS, Le Cessie S, Banwell P, et al. The effects of varying degrees of pressure delivered by negative-pressure wound therapy on skin perfusion. Ann Plast Surg 2005;55:665-671.

39. Borgquist $\mathrm{O}$, Ingemansson $\mathrm{R}$, Malmsjo $\mathrm{M}$. The effect of intermittent and variable negative pressure wound therapy on wound edge microvascular blood flow. Ostomy Wound Manage 2010;56:60-67.

40. Petersen SW, Rosin E. Cephalothin and cefazolin in vitro antibacterial activity and pharmacokinetics in dogs. Vet Surg 1995;24:347-351.

41. Kilpadi DV, Bower CE, Reade CC, et al. Effect of Vacuum Assisted Closure Therapy on early systemic cytokine levels in a swine model. Wound Repair Regen 2006;14:210-215.

42. Labler L, Rancan M, Mica L, et al. Vacuum-assisted closure therapy increases local interleukin-8 and vascular endothelial growth factor levels in traumatic wounds. J Trauma 2009;66:749-757.

43. Roberts WG, Palade GE. Increased microvascular permeability and endothelial fenestration induced by vascular endothelial growth factor. J Cell Sci 1995;108 ( Pt 6):2369-2379.

44. Owen LA, Hartnett ME. Soluble Mediators of Diabetic Macular Edema: The Diagnostic Role of Aqueous VEGF and Cytokine Levels in Diabetic Macular Edema. Curr Diab Rep 2013.

45. Mullner T, Mrkonjic L, Kwasny O, et al. The use of negative pressure to promote the healing of tissue defects: a clinical trial using the vacuum sealing technique. Br J Plast Surg 1997;50:194-199. 
46. Moues CM, Vos MC, van den Bemd GJ, et al. Bacterial load in relation to vacuum-assisted closure wound therapy: a prospective randomized trial. Wound Repair Regen 2004;12:11-17.

47. Weed T, Ratliff C, Drake DB. Quantifying bacterial bioburden during negative pressure wound therapy: does the wound VAC enhance bacterial clearance? Ann Plast Surg 2004;52:276-279; discussion 279-280.

48. Brakenburg A, Obdeijn MC, Feitz R, et al. The clinical efficacy and cost effectiveness of the vacuum-assisted closure technique in the management of acute and chronic wounds: a randomized controlled trial. Plast Reconstr Surg 2006;118:390-397; discussion 398-400.

49. Chester DL, Waters R. Adverse alteration of wound flora with topical negative-pressure therapy: a case report. Br J Plast Surg 2002;55:510-511.

50. Gwan-Nulla DN, Casal RS. Toxic shock syndrome associated with the use of the vacuum-assisted closure device. Ann Plast Surg 2001;47:552-554.

51. Papich MG, Davis JL, Floerchinger AM. Pharmacokinetics, protein binding, and tissue distribution of orally administered cefpodoxime proxetil and cephalexin in dogs. Am J Vet Res 2010;71:1484-1491.

52. Mouton JW, Theuretzbacher U, Craig WA, et al. Tissue concentrations: do we ever learn? J Antimicrob Chemother 2008;61:235-237.

53. Waterman NG, Raff MJ, Scharfenberger L, et al. Protein binding and concentrations of cephaloridine and cefazolin in serum and interstitial fluid of dogs. $J$ Infect Dis 1976;133:642-647. 
Table 1. Wound Randomization

\begin{tabular}{|c|c|c|}
\hline $\begin{array}{l}\text { Study } \\
\text { Dog }\end{array}$ & Right wound & Left wound \\
\hline Dog 1 & Group I (NPWT) & Group II (NA) ${ }^{*}$ \\
\hline $\operatorname{Dog} 2$ & Group II (NA) ${ }^{*}$ & Group I (NPWT) \\
\hline $\operatorname{Dog} 3$ & Group I (NPWT) & Group II (NA) $^{*}$ \\
\hline $\operatorname{Dog} 4$ & Group I (NPWT) & Group II (NA) ${ }^{*}$ \\
\hline Dog 5 & Group II (NA) ${ }^{*}$ & Group I (NPWT) \\
\hline Dog 6 & Group II (NA) ${ }^{*}$ & Group I (NPWT) \\
\hline $\operatorname{Dog} 7$ & Group I (NPWT) & Group II (NA) $^{*}$ \\
\hline $\operatorname{Dog} 8$ & Group I (NPWT) & Group II (NA) $^{*}$ \\
\hline $\operatorname{Dog} 9$ & Group I (NPWT) & Group II (NA) \\
\hline Dog 10 & Group II (NA) * & Group I (NPWT) \\
\hline Dog 11 & Group I (NPWT) & Group II (NA) ${ }^{*}$ \\
\hline $\operatorname{Dog} 12$ & Group I (NPWT) & Group II (NA) ${ }^{*}$ \\
\hline
\end{tabular}


Fig 1. Antebrachial Wound Outline

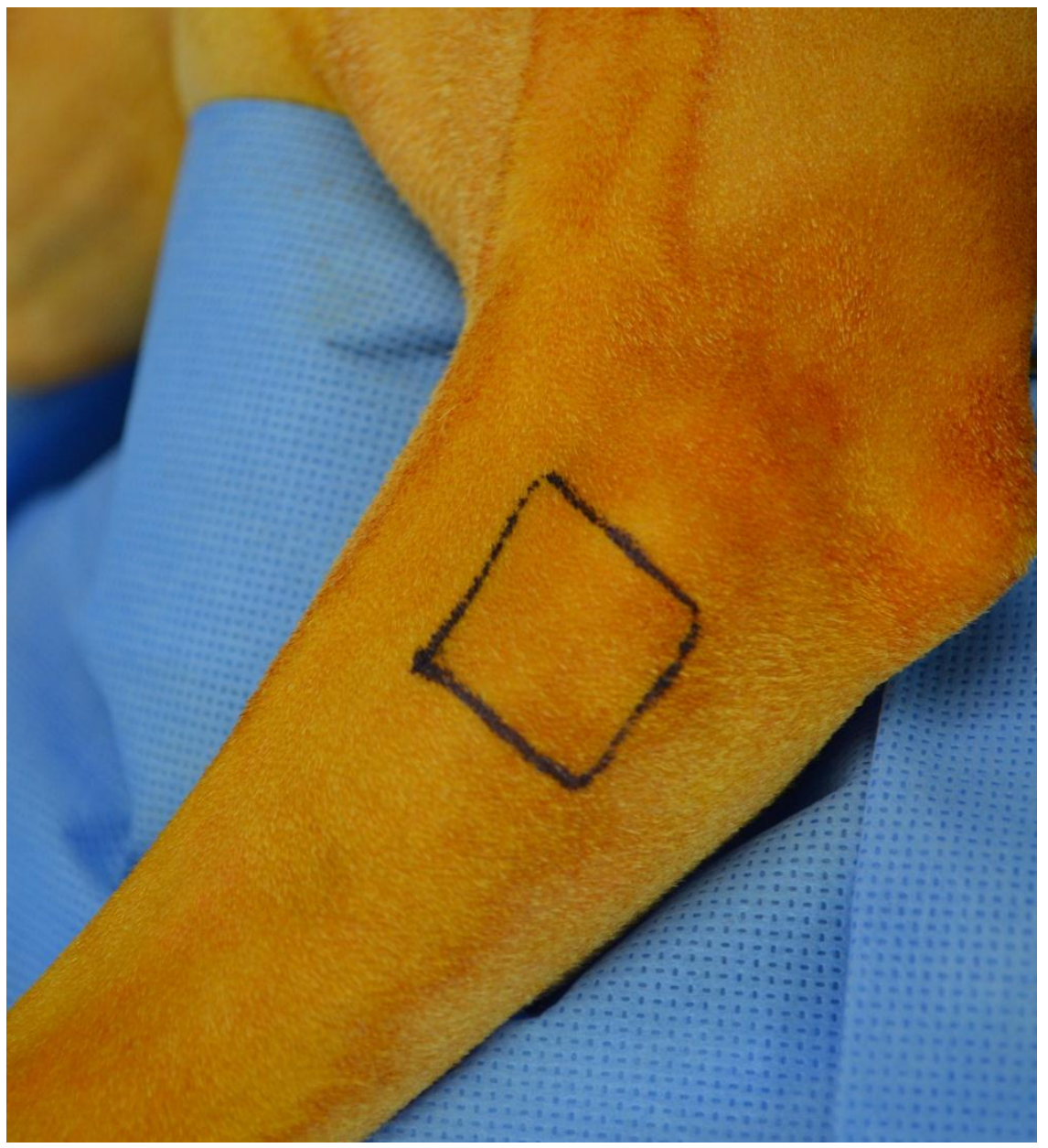

Fig. 1

The outlined $2 \mathrm{~cm} \times 2 \mathrm{~cm}$ square on the lateral aspect of the dog's antebrachium was made on the initial day of wound creation prior to bandage application. This outlined the full thickness skin defect which was created. Each wound was created on the lateral aspect of the antebrachium $2.5 \mathrm{~cm}$ distal from the proximal aspect of the olecranon. The right antebrachial wound was randomly assigned to group I or group II based on a coin toss. The contralateral antebrachium was then assigned to the other group. 
Fig. 2 VAC Simplicity Unit

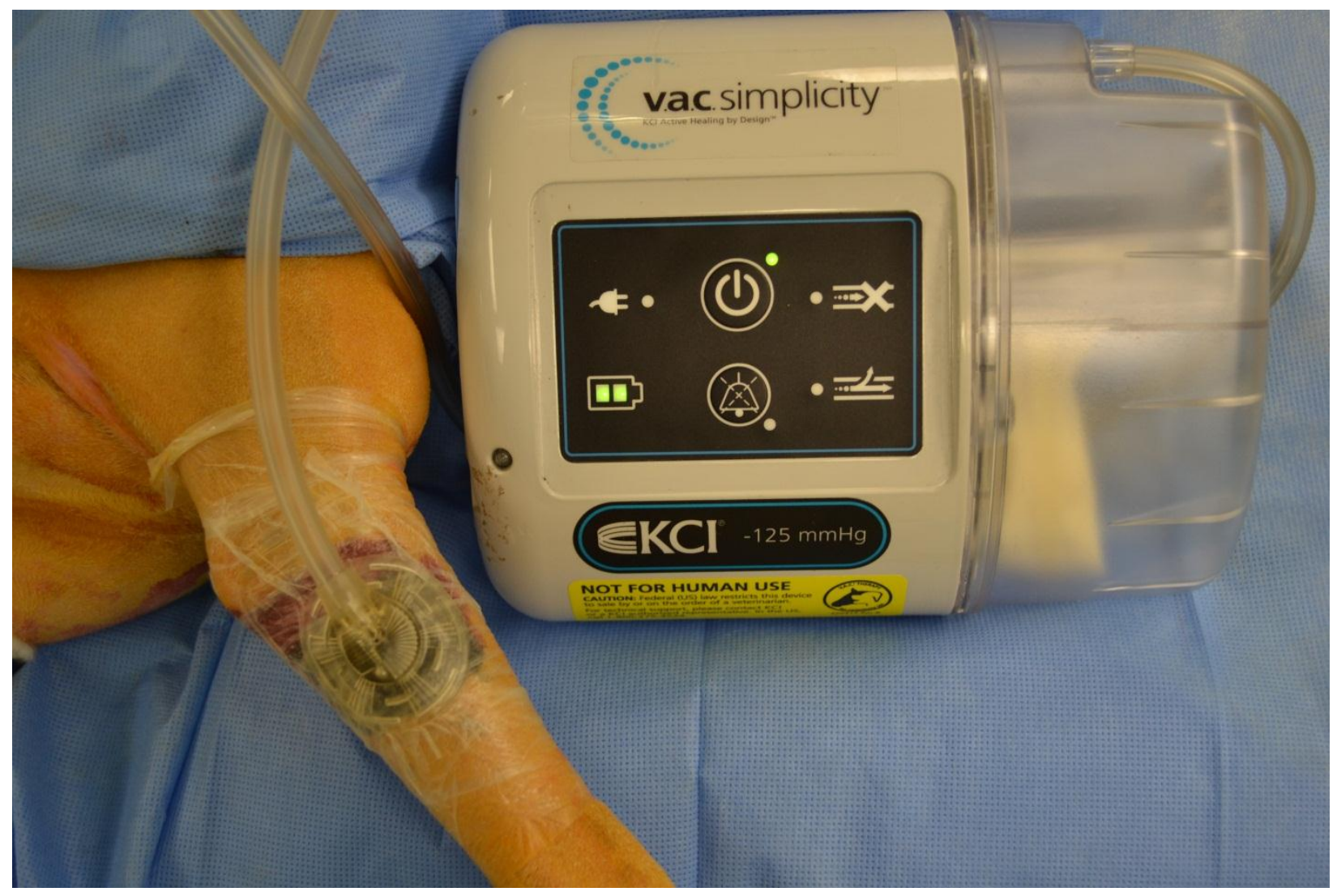

Fig. 2

The VAC Simplicity unit (V.A.C. ${ }^{\circledR}$ Simplicity ${ }^{\mathrm{TM}}$, Kinetic Concepts Inc., San Antonio, TX) is displayed above. The antebrachium in the image was assigned to Group I and the image was taken after NPWT bandage assembly with foam dressing, selfadhesive drape, perforated disc, evacuation tube and vacuum system. 
Fig. 3 Representative Study Dog

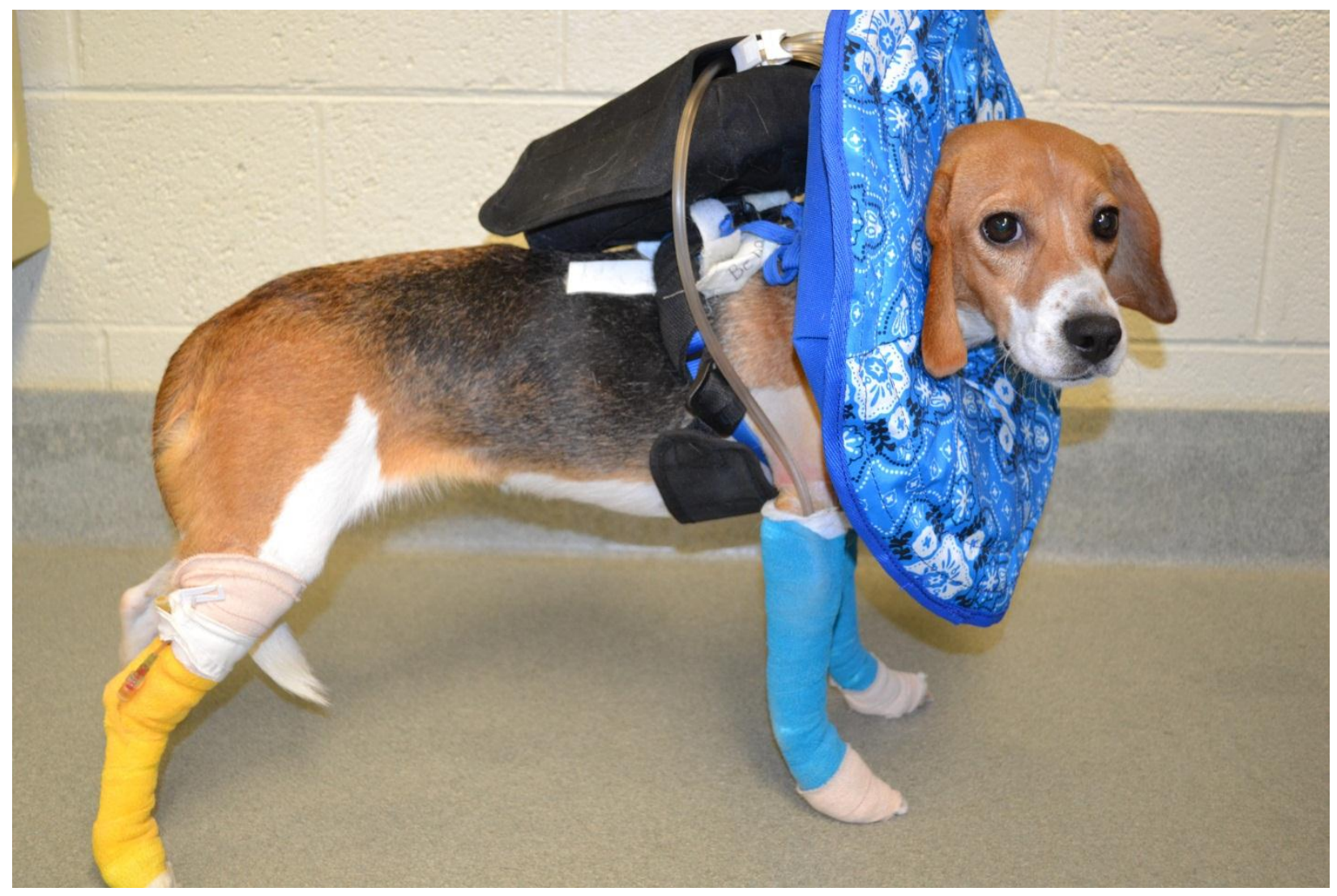

Fig. 3

Displayed is a dog in the study with bandages on each antebrachium from digits to just proximal to the cubital joint. The VAC Simplicity unit was attached to a patient harness to allow for mobility and prevent destruction of the bandages. The forelimbs were bandaged for either group I or group II as decided by coin toss. The lateral saphenous was also used for placement of a long indwelling intravenous catheter as displayed above. 
Fig. 4 Tissue Cefazolin Concentration

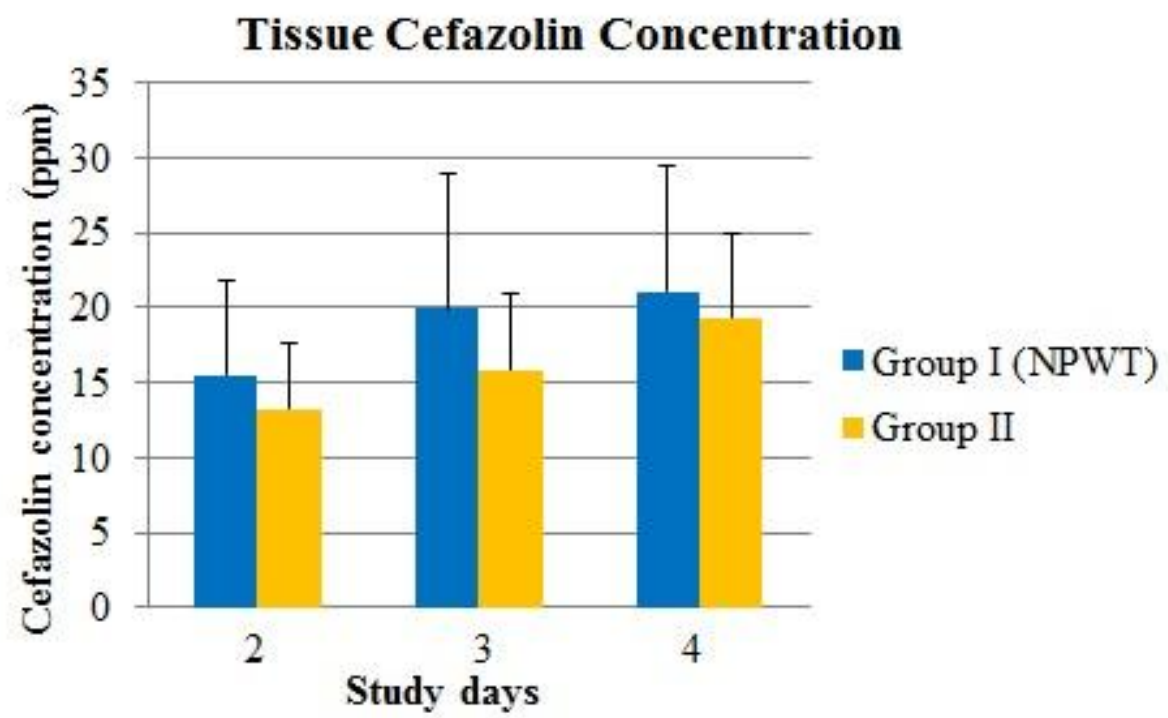

Fig. 4

Bar graphs of the mean tissue cefazolin concentration presented in parts per million (ppm) of wound biopsies. Error bars represent one standard deviation. Cefazolin $22 \mathrm{mg} / \mathrm{kg}$ was administered intravenously every 8 hours to the 12 dogs in the study. Group I (NPWT treated wounds) and Group II (nonadherent dressing treated wounds) wound tissues were biopsied on study days 1-4 with a $4 \mathrm{~mm}$ biopsy punch. Tissue samples were analyzed by LC-MS/MS. Study days 2-4 are displayed as cefazolin was administered after tissue biopsies were obtained on study day 1 . 


\section{Conclusion}

In our investigation, our primary goal was to compare cefazolin concentration in surgically created wounds treated with NPWT to cefazolin concentration in wounds treated with nonadherent dressings. Based on our clinical impressions, we hypothesized that there would be significant differences between the cefazolin concentration in wounds treated with NPWT or nonadherent dressings. As a secondary purpose of our investigation, we compared aerobic and anaerobic wound cultures taken at the time of bandage changes. Our results and discussion appear at length in the research presented here; however, two statements serve to summarize our findings: 1) there was no significant different between cefazolin concentrations in wounds treated with NPWT or nonadherent dressings 2) there was no significant difference in wound cultures between treatment groups at any point in the study. Based on these observations we concluded that cefazolin tissue concentrations were similar between groups and therefore systemic cefazolin delivery to wounds treated with NPWT can be expected to be similar to the delivery in wounds treated with traditional nonadherent dressings. Prior to these results,

there was debate if NPWT decreases bacterial burden in wounds. This inspired our group to investigate whether the beneficial effects of NPWT were due to difference in antibiotic concentration to the treated wounds or a difference in the wound bacterial burden. The complex mechanisms by which NPWT benefits wound healing is an interesting area that warrants further investigation, and we believe that the principal significance of our findings will add to the knowledge of the mechanism by which NPWT promotes wound healing and development of granulation tissue formation. Our observations may lead to a 
greater research focus relating to the mechanisms of how NPWT improves wound healing in the acute period. 